\title{
Impact of a MTHFR-deficiency on focal ischemic damage to the sensorimotor cortex in aged mice
}

by

\author{
Joshua T. Emmerson
}

A thesis submitted to the Faculty of Graduate and Postdoctoral Affairs in partial fulfillment of the requirements for the degree of

Master of Science

in

Neuroscience

Carleton University

Ottawa, Ontario, Canada

(C) 2017

Joshua T. Emmerson 


\section{Acknowledgements}

I would like to take this opportunity to thank many individuals for their continuous support in assisting with the development of this thesis document, the research it contains, the invaluable learning experiences and the skills attained throughout the duration of this program to further my academic interests and professional development.

I would first and most importantly like to thank, Drs. Patrice Smith and Nafisa Jadavji, as their teachings, training, support and guidance were paramount in this endeavor. Without them this would not have been possible and I hold undying gratitude throughout my lifetime for taking me under their wings. Second, I would like to, in addition to Nafisa and Patrice, thank the members of my thesis committee including Drs. Shawn Hayley, Michael Hildebrand, and Bill Willmore for their feedback and testimony to academic integrity for this thesis. I would also like to acknowledge the professors of the department of neuroscience that have made significant contributions to increasing my knowledge of neuroscience and to the administrative staff that have facilitated these processes. I also acknowledge the additional morale support of classmates, members of the Smith lab, friends and family in these academic endeavors, as they have enriched my experience here at Carleton University.

Lastly, I would like to dedicate this thesis in the name of my grandfather Joshua John, who has always been an exemplary role model that encourages the quality of hard work, passion, as well as the value of a higher education, and to my Grandmother, Una John, who suffered from neurogenerative disease for several years before passing in July 2016. May this degree be an important stepping stone to finding ways of stopping the suffering of the elderly in the future. 
Table of Contents

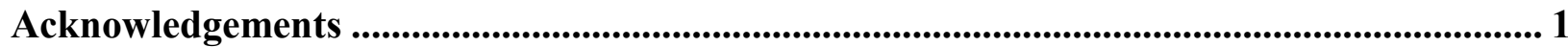

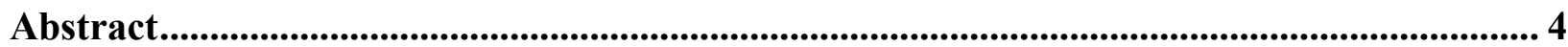

List of Abbreviations .......................................................................................................................... 5

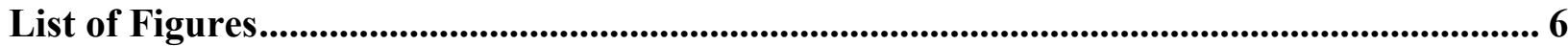

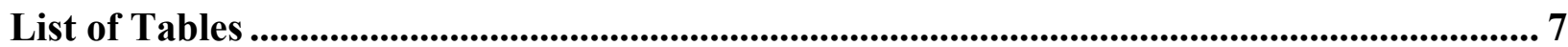

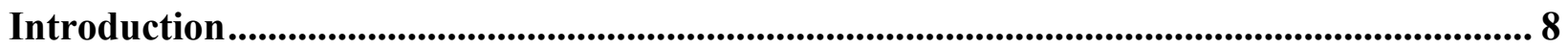

Importance of studying stroke ........................................................................................ 8

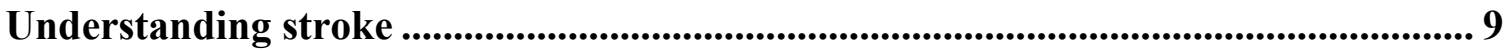

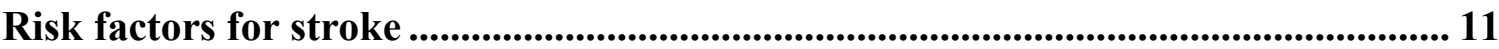

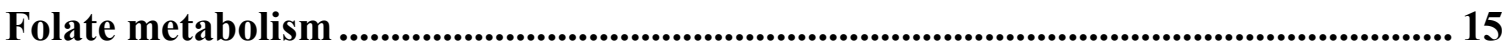

Homocysteine, folate and stroke ....................................................................... 16

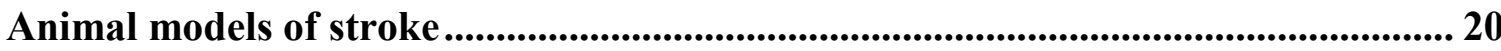

Current animal studies: folate, homocysteine and stroke ....................................... 23

MTHFR mouse model ...................................................................................................... 24

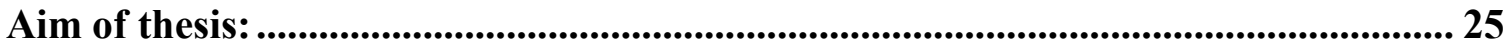

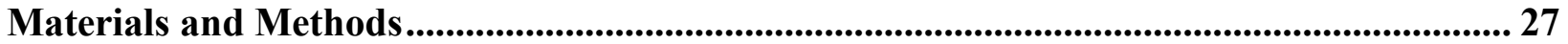

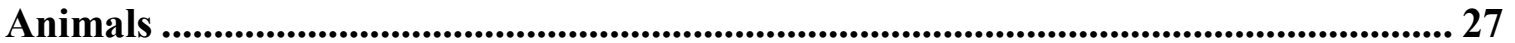

Experimental design ............................................................................................................... 29

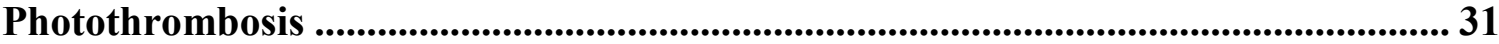

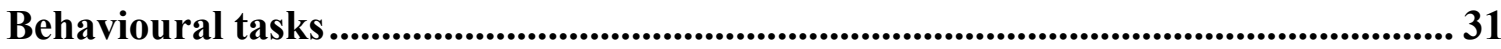

Single pellet reaching task ....................................................................... 31

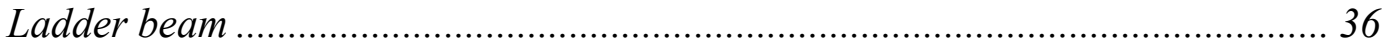

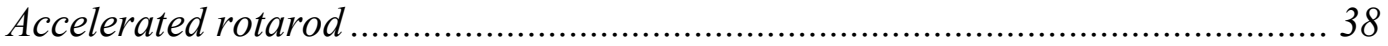

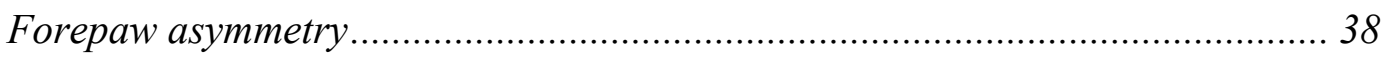

Plasma homocysteine concentration .............................................................................. 38

Lesion volume

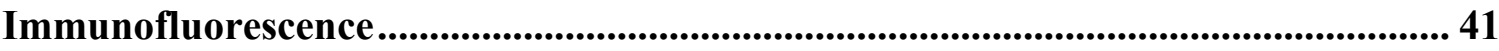

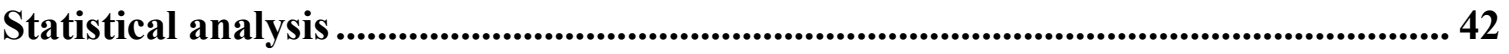

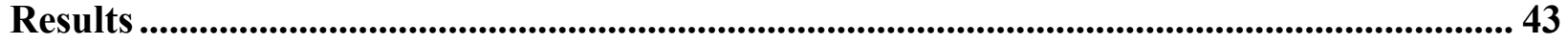

Skilled reaching: single pellet reaching task .................................................................... 43 


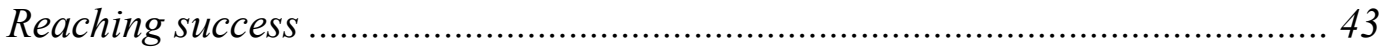

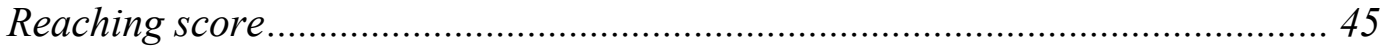

Skilled walking: ladder beam ......................................................................... 47

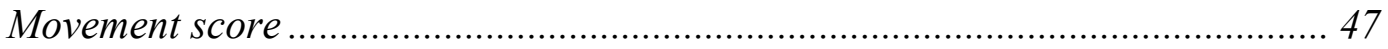

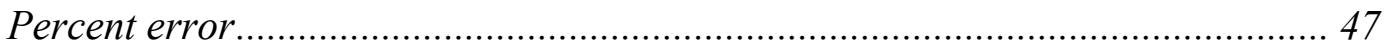

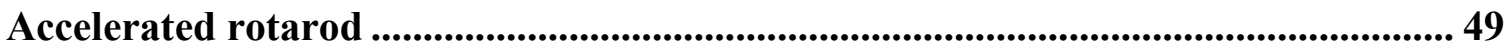

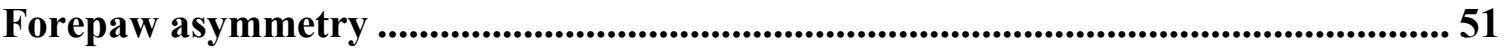

Plasma homocysteine concentration ............................................................................ 53

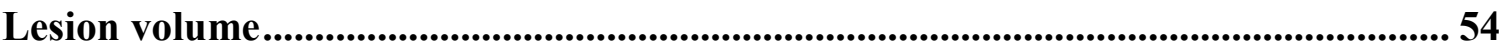

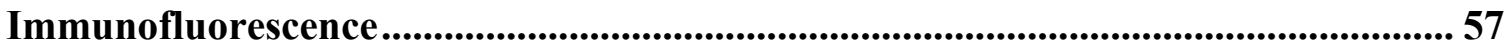

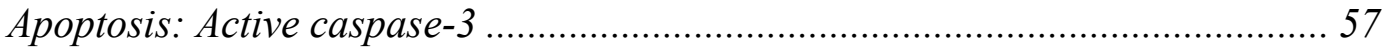

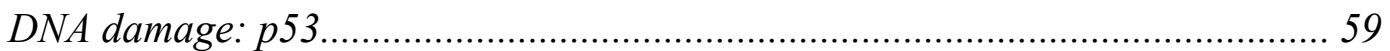

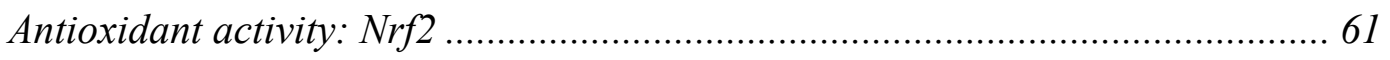

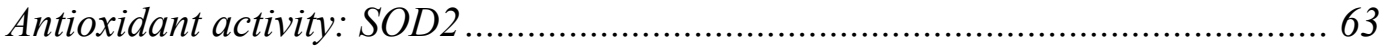

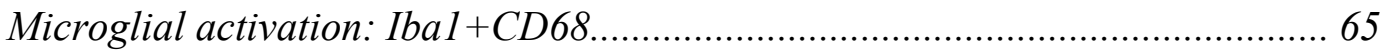

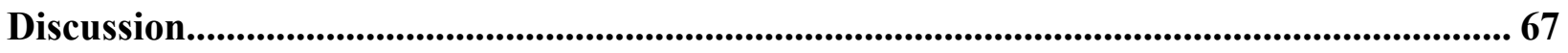

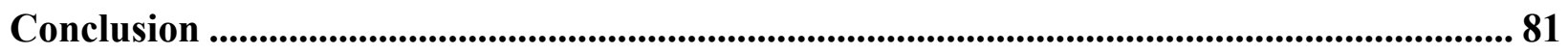

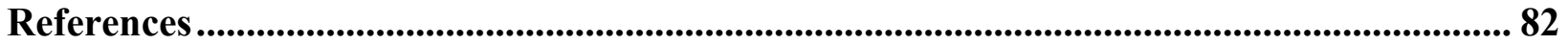




\begin{abstract}
Effective therapeutics in stroke are presently limited by a lack of translation from basic science to the clinic. Accumulation of excess plasma homocysteine is a risk factor for stroke. The B-vitamin, folate, helps to reduce plasma homocysteine among other important roles in the normal and diseased brain. Methylenetetrahydrofolate reductase (MTHFR) is the pivotal enzyme in folate metabolism that helps reduce homocysteine and could potentially modify stroke outcome. There is a highly prevalent polymorphism for Mthfr within the human population resulting in a MTHFR deficiency and elevated plasma homocysteine levels. The present study investigates the impact of a MTHFR deficiency on stroke outcome using a clinically relevant aged mouse model that mimics the MTHFR polymorphism in humans. Eighteen-month-old male C57BL/6N mice were subjected to photothrombosis delivered unilaterally to the sensorimotor cortex followed by assessment of motor function including the single pellet reaching task for up to 5 weeks, the ladder beam, the accelerated rotarod and the forepaw asymmetry task. Lesion volume and immunofluorescence of apoptotic, antioxidant and inflammatory activity were assessed. MTHFR deficient mice show significant impairments in skilled reaching for up to 5 weeks. After 5 weeks, caspase-3 expression was significantly elevated at the ischemic core of MTHFR deficient mice. No significant changes in motor function, lesion volume, antioxidant activity nor microglial cell activation were detected. Regardless of damage, MTHFR deficient mice showed elevated levels of plasma homocysteine. This study is the first to demonstrate in vivo exacerbation of stroke outcome in a MTHFR deficient animal model.
\end{abstract}

Key words: homocysteine, ischemia, methylenetetrahydrofolate reductase, photothrombosis, sensorimotor cortex, motor function 


\section{List of Abbreviations}

ANOVA - Analysis of variance

BHMT - Betaine-homocysteine S-methyltransferase

CBS - Cystathionine $\beta$-synthase

Cas-3 - Caspase-3

CD68 - Cluster of Differentiation 68

DHFR - Dihydrofolate reductase

DHF - Dihydrofolic acid

DMG - Dimethylglycine

ET-1 - Endothelin 1

FMA - Fugl-Meyer Assessment

Iba1 - Ionized calcium binding adapter molecule 1

ICAM1 - Intercellular Adhesion Molecule 1

IPC - Ischemic preconditioning

IL-4, 6, 8, 17 - Interleukin 4, 6, 8, 17

Hcy - Homocysteine

Hhcy - Hyperhomocysteinemia

MCAO - Middle cerebral artery occlusion

MCP-1 - Monocyte chemoattractant protein-1

MIP-1g - Macrophage inflammatory protein 1 gamma

MnSOD* - Manganese superoxide dismutase (same as SOD2)

MTHFR - Methylenetetrahydrofolate reductase

MTR - Methionine synthase

$\mathrm{NO}$ - Nitric oxide

Nrf2 - Nuclear factor like 2

PARP - Poly-ADP-ribose polymerase

PFA - Paraformaldehyde

PFT- $\alpha-$ p53 inhibitor pifithrin- $\alpha$

PT - Photothrombosis (treatment group)

ROS - Reactive oxygen species

SAM - S-adenosyl methionine

SAH - S-adenosyl homocysteine

SHMT - Serine hydromethyltransferase

SOD2* - Superoxide dismutase 2 (same as MnSOD)

SNP - Single nucleotide polymorphism

THF - Tetrahydrofolate

TNFR1, 2 - Tumor necrosis factor receptor 1, 2

tPA - Tissue plasminogen activator

TS - Thymidylate synthase

TUNEL - Terminal deoxynucleotidyl transferase dUTP nick end labeling 


\section{List of Figures}

Title

Figure 1. A summary of folate and homocysteine metabolism in the cell................................... 14

Figure 2. Schematic of photothrombosis-induced ischemic damage in mice............................. 22

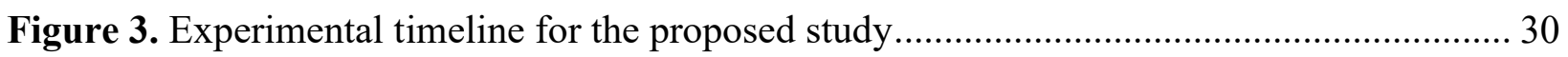

Figure 4. The reaching apparatus for the single pellet reaching task in mice............................. 33

Figure 5. Coronal slice of a mouse brain highlighting important cortical regions ..................... 40

Figure 6. Quantitative assessment of the single pellet reaching task ......................................... 44

Figure 7. Qualitative analysis of the single pellet reaching task ................................................ 46

Figure 8. Assessment of skilled motor function on the ladder beam walking task...................... 48

Figure 9. Assessment of balance and coordination in by the accelerated rotarod ....................... 50

Figure 10. Forepaw asymmetry scores of motor function ..................................................... 52

Figure 11. Plasma homocysteine concentrations $(\mu \mathrm{M})$ in aged $M t h f r^{+/+}$and $M t h f r^{+/}$mice........ 54

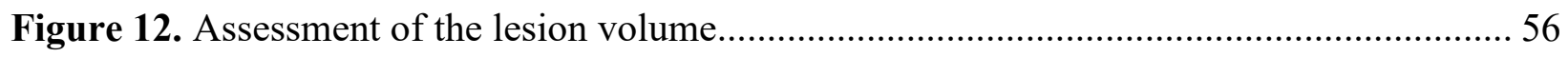

Figure 13. Representative immunofluorescence images of active Caspase- 3 ………….............. 58

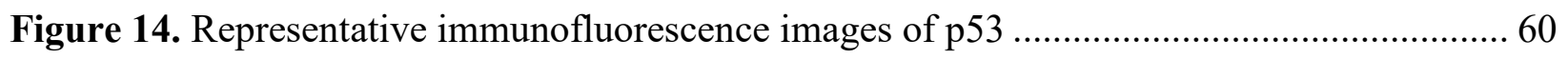

Figure 15. Representative immunofluorescence images of Nrf2 ................................................ 62

Figure 16. Representative immunofluorescence images of SOD2 ….......................................... 64

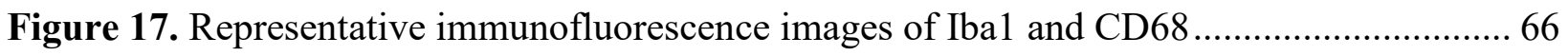




\section{List of Tables}

Title

Page

Table 1. Comparison of mature life history stages in aging between humans and mice ............ 28

Table 2. Qualitative assessment of the single pellet reaching task ...................................... 35

Table 3. Qualitative assessment of the the ladder beam task .............................................. 37 


\section{Introduction}

\section{Importance of studying stroke}

Cardiovascular disease is one of the leading causes of death in North America and as aging occurs, individuals are more at risk (Heart and Stroke Foundation, 2016). Age has been identified as the most important non-modifiable risk factor for all subtypes of stroke, particularly ischemic stroke (WHO MONICA Project Principal Investigators, 1988; Feigin et al., 2015). The occurrence of stroke is greater and the functional outcome is more severe in aged individuals, however, individuals of any age may suffer from a stroke (Kelly-Hayes et al., 2003; Long et al., 2016; Vijayan and Reddy, 2016). Stroke is considered a major health and economic problem worldwide and, more importantly, it is a growing burden in the current increasingly aging population (Feigin et al., 2015; Mozaffarian et al., 2015). For example, in Canada the number of people over the age of 65 outnumbers the ones under 15 (Statistics Canada, 2015), therefore the need to further understand and develop effective therapies for affected individuals is urgent.

Currently there is a lack of translational research, such that, almost none of the reported neuroprotective therapies that were beneficial in animal models have benefited in stroke affected human patients after damage (Dirnagl, 2016). Currently, the only approved treatment for stroke is the administration of intravenous tissue plasminogen activator (tPA) (Jauch et al., 2013; Alawieh et al., 2016; Broome et al., 2016). tPA plays an important physiological role in coagulation homeostasis by stimulating fibrin-based clot dissolving (Bonaventura et al., 2016). However, there are limitations to tPA administration. For example, it is only recommended if the stroke event occurred within 3.5 to 4 hours of treatment otherwise the treatment becomes not only significantly less effective but also may induce hemorrhaging (Lees et al., 2010; Jauch et al., 2013). Although this intervention exists to restore blood flow shortly after a stroke event, no 
concrete method of prevention and no treatment to reverse the effects of stroke currently exist. Based on what has been found, perhaps establishing a preventative approach to minimize both the risk and severity of a stroke event is attainable from a better understanding of risk factors and mechanisms involved in regulation of stroke outcome.

\section{Understanding stroke}

Stroke represents a major subset of cardiovascular cases. It is a broad term that encompasses several different types of physiological events, each causing neurological dysfunction from ischemic conditions in the brain (Sacco et al., 2013). Generally, stroke occurs when a significant blood clot, termed a thrombus, forms in the circulatory system and this prevents proper delivery of oxygen and nutrients to the brain, which is essential for proper function (Sacco et al., 2013; Kumar et al., 2016). As a result, neurons and glial cells begin to die causing significant brain damage and this eventually leads to functional impairments (Sacco et al., 2013). More specifically, stroke is categorized as either ischemic or hemorrhagic (Sacco et al., 2013; Ansari et al., 2014). An ischemic stroke occurs when a blood clot forms inside of the vasculature within the brain such as a cerebral artery. This type of stroke event is the most common, occurring in $\sim 87 \%$ of all stroke cases (Mozaffarian et al., 2015). Alternatively, hemorrhagic stroke is when a weakened blood vessel ruptures causing bleeding in the brain. The leaked blood accumulates and compresses the surrounding brain tissue (Kumar et al., 2016). A stroke, whether ischemic or hemorrhagic, can also be silent which means that there is evidence of a CNS infarction, but there is no visible impairments in function (Sacco et al., 2013).

After an ischemic stroke, there is a patterned area of damaged cells consisting of two unique features: the ischemic core and the ischemic penumbra. The core is the central area of damage that has severely ischemic tissue and this area consists of dying neurons and glia. The 
penumbra, also called the peri-infarct region, is the area that surrounds the core and has mild to moderate ischemic tissue. It also is the region where glial scar formation occurs to protect the rest of the brain from further damage (Huang et al., 2014). The penumbra in particular has been a primary therapeutic target as it is found to be salvageable if reperfusion is established within the first few hours of the ischemic event (Liu et al., 2012). Unfortunately, most stroke patients do not arrive at the hospital until approximately 24 hours after symptoms appear which is too late for treatment (Kolb and Whishaw, 2011). The duration, severity of blockage and location of the ischemic stroke all affect the overall severity of damage to the brain. For example, ischemic stroke can either be focal or global. Focal strokes, which are more common, are specific to a small area of the brain whereas global strokes affect all parts of the brain. Nonetheless, after a stroke event where the sensorimotor cortex is damaged, motor function of the body becomes compromised contralateral to the damage in the brain. Because there is decussation of sensory neurons at the midbrain, stroke in the right hemisphere affects sensation and movement in the left side of the body (Kolb and Whishaw, 2011).

Despite understanding the process of a stroke, how it causes neurodegenerative pathology is not completely understood (Busl and Greer, 2010). For example, the amount of functional damage that a stroke can cause varies between people and can range from mild to moderate to severe (Heart and Stroke Foundation, 2016). It is important to consider the possible influence of other factors that are recognized as contributors to increased severity and prevalence of stroke. Research has therefore been dedicated to identifying risk factors associated with stroke and, most recently, understanding the molecular physiology of stroke to ultimately discover more effective therapeutic targets to prevent and minimize stroke outcome, respectively. 


\section{Risk factors for stroke}

Common non-modifiable risk factors for stroke such as age and family history, as well as modifiable risk factors such as smoking status and diet have been previously established (Mozaffarian et al., 2015; Kumar et al., 2016). More importantly, recent findings have strongly associated increased levels of plasma homocysteine (Hcy) with increased risk of cardiovascular disease such as stroke (Castro et al., 2006; Santilli et al., 2016). In fact, elevated levels of homocysteine $(>12 \mu \mathrm{mol} / \mathrm{L}$ compared to $5-10 \mu \mathrm{mol} / \mathrm{L}$ in healthy adults (Obeid et al., 2007; Hainsworth et al., 2015)), termed hyperhomocysteinemia, is considered an independent risk factor for stroke (Brattstrom et al., 1992). Homocysteine is a non-protein amino acid product of methylation reactions in cells that can be measured in blood. The Homocysteine Studies Collaboration published in 2002 compiled and reviewed literature from over 30 prospective or retrospective studies, totalling 1113 stroke patients associating a $25 \%$ reduction in plasma homocysteine levels with a 19\% reduction in risk for stroke (The Homocysteine Studies Collaboration, 2002). Recently, this association was emphasized in European countries including Italy and Poland as well as Asian countries such as China, Korea and Japan (Fu et al., 2015). Of these 13 studies, the initial results from a total of 1206 stroke patients and 1202 controls, having co-factors of stroke risk unaccounted for, reported mixed relationships between plasma homocysteine and stroke. Interestingly, when co-factors such as age, smoking status and history of cardiovascular disease among others were accounted for, the overall association between plasma homocysteine levels and risk for stroke is positively correlated.

Despite finding a significant association between elevated homocysteine levels and risk of stroke, the mechanism by which this association promotes stroke occurrence remains unclear (Castro et al., 2006; Christopher et al., 2007). This is, in part, because multiple factors and/or 
processes are associated with elevated levels of homocysteine and, as a result, homocysteine is prevalent in multiple neurodegenerative pathologies of the central nervous system (Obeid et al., 2007; Ansari et al., 2014) including risk of stroke, vascular dementia (Wald et al., 2002), cognitive impairment (Agrawal et al., 2015; Smith and Refsum, 2016), Parkinson's Disease (Isobe et al., 2005), Alzheimer's Disease and aging (McIlroy et al., 2002; Seshadri and Beiser, 2002; Morris, 2003). Among these findings, it appears as though hyperhomocysteinemia may promote an increased risk of stroke from downstream effects of decreased global DNA methylation (Baccarelli et al., 2010), increased endothelial dysfunction (Castro et al., 2006) and/or increased oxidative damage of cells (Kim and Pae, 1996; Pniewski et al., 2003; Obeid and Herrmann, 2006), making normally functional systems more susceptible to damage. Homocysteine has been shown to suppress nitric oxide (NO) production by endothelial cells and platelets and increases reactive oxygen species (ROS) production via arachidonic acid (Lehotsky et al., 2014). It is very likely that homocysteine may be involved in promoting mechanisms of neurodegeneration. Nonetheless, a homocysteine removal therapy has been proposed to attempt to reduce the risk of stroke (Obeid et al., 2007).

The biochemical and metabolic process of reducing homocysteine has been previously described (Olszewski and McCully, 1993; Perla-Kajan et al., 2007) and have been summarized (Figure 1). In brief, $S$-adenosylmethionine (SAM) donates a methyl group to newly synthesizing DNA and proteins resulting in conversion to S-adenysylhomocysteine (SAH). The ratio of SAM to SAH has been used as a measure of methylation status (Obeid and Herrmann, 2006; Obeid et al., 2009; Joubert et al., 2016; Smith and Refsum, 2016). High SAH relative to SAM is associated with a state of hypomethylation because this indicates a less amount of available methyl groups to donate. Over time, SAH is then hydrolyzed into homocysteine and this product 
can accumulate in cells. Homocysteine can be removed in three ways. In all cells, more importantly in the brain, homocysteine is primarily recycled into methionine using folate as a methyl donor. Interestingly, homocysteine metabolism in the brain is different than other organs because the transsulfuration pathway, for example, does not occur and remethylation of homocysteine via betaine is absent (Lehotsky et al., 2014). Homocysteine is removed by transsulfuration only in liver, pancreatic and renal tissue (Brosnan et al., 2004). This process requires pyridoxal (Vitamin $\mathrm{B}_{6}$ ) as a coenzyme, serine and cystathionine $\beta$-synthase (CBS) to convert homocysteine into cystathionine. Homocysteine can also be recycled into methionine by choline metabolism. Choline is converted to betaine which is used by betaine-homocysteine Smethyltransferase (BHMT). BMHT is restrictively expressed in the liver and kidney and is not present in the brain of rodents however it has recently been shown to be present in brains of bats (Zhang et al., 2013). In addition to this paradigm, betaine has also been shown to be lowered in both hyperhomocysteinemic patients (plasma) and rats (liver, kidney and brain tissue), highlighting a potential but unknown role of betaine in this regard (Jadavji et al., 2012; Imbard et al., 2015). More importantly, in the brain, several of the mentioned association studies have indeed highlighted an important potential role of folate and folate metabolism in homocysteine removal. 


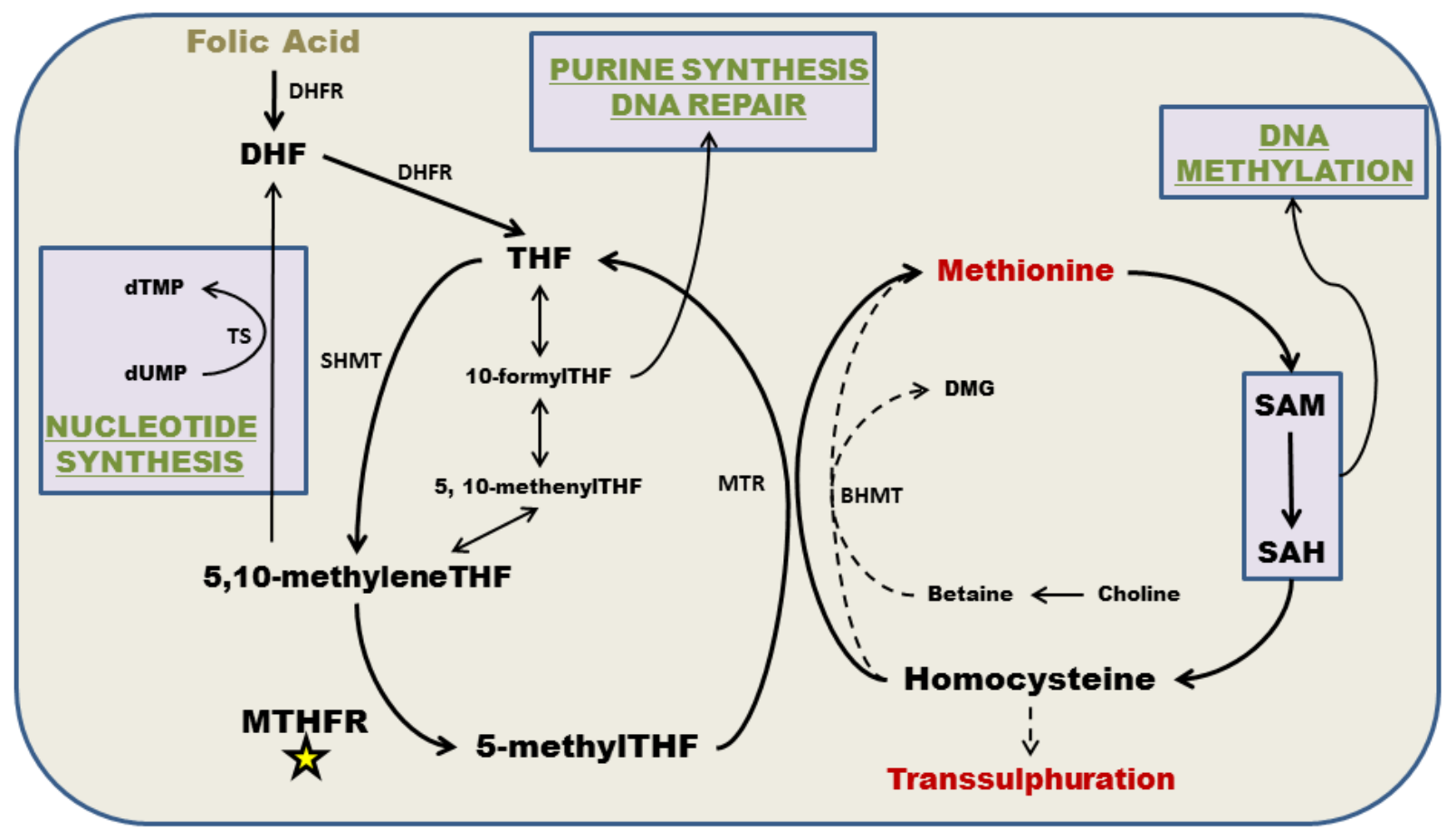

Figure 1. A summary of folate and homocysteine metabolism in the cell. Dashed lines indicate other cellular processes absent in the brain. $\mathrm{DHFR}=$ dihydrofolate reductase; $\mathrm{DHF}=$ dihydrofolic acid; $\mathrm{THF}=$ tetrahyrofolate; $\mathrm{SHMT}=$ serine hydromethyltransferase; $\mathrm{MTHFR}=$ Methylene tetrahydrofolate reductase; $\mathrm{MTR}=$ Methionine synthase; $\mathrm{TS}=$ Thymidylate synthase; SAM= S-adenosyl methionine; SAH= S-adenosyl homocysteine; BHMT= betainehomocysteine S-methyltransferase; DMG = dimethylglycine. Modified from (Jadavji et al., 2015; Perla-Kajan et al., 2007). 


\section{Folate metabolism}

Folate is an essential B-vitamin that is involved in nucleotide synthesis as well as methylation reactions in the cell. It is synthesized from gut microbiota but the amount generated is not sufficient to meet bodily demands (Hill, 1997; Rossi et al., 2011). Therefore, natural folates are predominantly obtained from the diet such as spinach and dark green legumes. Folate supplementation is also obtainable via folic acid (Vitamin $\mathrm{B}_{9}$ ) which is an oxidized synthetic version. The most commonly known role of folates is to prevent neural tube defects in developing fetuses (Castillo-Lancellotti et al., 2012). In fact, this was the reason for a mandatory fortification initiative in North America in which foods such as grains were enriched with folate in hopes to reduce the amount of neural tube defects. Once folic acid enters cells, it is broken down and is transformed into a form that is used as a methyl donor (Figure 1). In brief, folic acid is reduced by dihydrofolate reductase (DHFR) into dihydrofolic acid (DHF) and then further reduced to tetrahydrofolate (THF). Folates come in different forms, but the most versatile form is tetrahydrofolate (TFH). THF is versatile because it can be allocated towards purine synthesis and DNA repair, nucleotide synthesis or homocysteine removal. More importantly, in the latter, THF is converted into 5, 10-methylenetetrahydrofolate $(5,10$-methyleneTHF $)$ by serine hydroxymethyltransferase (SHMT). 5, 10-methyleneTHF is then reduced by methylenetetrahydrofolate reductase (MTHFR) to 5-methyltetrahydrofolate (5-methylTHF), known as an important methyl donor and the main circulating form of folate (Castro et al., 2006; Yuan et al., 2009; Jadavji et al., 2015b). Therefore, MTHFR is a pivotal enzyme in folate metabolism for the synthesis of methyl donors and a reduction in the amount of MTHFR as well as its enzymatic efficiency results in reduced circulating folate. After 5-methylTHF is 
synthesized, methionine synthase (MTR) then takes the methyl group to methylate homocysteine into methionine, converting 5-methylTHF back into THF in the process.

\section{Homocysteine, folate and stroke}

Folates play an important role in directly reducing homocysteine levels in cells (Figure 1). Because of the strong association between homocysteine and cardiovascular disease, folates have also recently been shown to also play a role in cardiovascular disease. One explanation for hyperhomocysteineimia is reduced folate availability among others (Spence, 2007), as a lack of methyl donors for homocysteine in brain cells prevents its recycling back into methionine. Folate availability, or folate status, are terms used to describe the relative amount of available folate in cells for methyl group donation. Many studies have shown that there is a strong negative correlation between plasma homocysteine and folate status (Schwammenthal and Tanne, 2004; Holmes et al., 2011; Jiang et al., 2014), indicating that patients with increased folic acid intake have reduced plasma homocysteine. The causes for reduced folate status have been identified as either a reduced dietary intake of folates or a deficiency in folate metabolism.

Studies investigating the effect of dietary folate status on homocysteine levels have shown that B-vitamin supplementation is effective at removing homocysteine, however, the clinical outcomes have been mixed especially with regards to cardiovascular disease (Wald et al., 2002; Meschia et al., 2014). A sufficient B-vitamin status has been shown to help reduce levels of homocysteine, and by extension, risk of stroke, but evidence is not strong enough. For example, one meta-analysis performed in 2010 consisting of 8 randomized trials and totalling 37,485 individuals found that folic acid supplementation reduced homocysteine levels by on average $25 \%$ but had no significant effect on cardiovascular events (defined as coronary events, strokes and revascularizations) even when isolating specific events (Clarke et al., 2010). Later 
reviewed in 2014, vitamin supplementation with B-vitamins in 12,064 survivors did not show any significant benefit to reducing cardiovascular disease (Desai et al., 2014). Recently, the China Stroke Primary Prevention Trial (CSPPT), examining 20,702 hypertensive patients without history of stroke or myocardial infarction, demonstrated that folic acid supplementation over time significantly reduced relative stroke risk by $\sim 21 \%$ when administered with the hypertensive medication Enalapril (Huo et al., 2015). Similarly, the Heart Outcomes Prevention Evaluation 2 (HOPE2) trial found that therapies involving folic acid, Vitamin $\mathrm{B}_{6}$ and Vitamin $\mathrm{B}_{12}$ reduced the overall risk of stroke (Saposnik et al., 2009). Regardless, epidemiological data has thus far not clearly demonstrated that B-vitamin supplementation, resulting in reduced plasma homocysteine, reduces risk for stroke and is therefore inconclusive (Meschia et al., 2014). One factor yet to be considered for these studies having mixed findings is that some countries, such as those in North America, have mandatory fortification of folate in foods whereas others, such as China, do not. This may be an important confound to address which emphasizes the dietary impacts and overall outcomes on clinical results. Studies in countries with folate fortification may not show a significant relationship compared to non-fortified countries because fortification significantly reduces the sensitivity of detecting, or masks the presence of, any relationship between B-vitamin based homocysteine removal and risk of stroke.

Alternatively, reduced folate availability attributed to a deficiency in folate metabolism may be another more promising avenue. Given a sufficient dietary intake of folate, the inability of cells to metabolize and utilize it properly is thought to hinder homocysteine removal significantly. Deficiencies in folate metabolism have been heavily associated with reduced methylenetetrahydrofolate reductase (MTHFR) activity (Frosst et al., 1995). MTHFR is evolutionarily conserved enzyme and a few single nucleotide polymorphisms (SNPs) have 
interestingly been identified (Khan and Jamil, 2008; Kumar et al., 2015). For example, a polymorphism in the Mthfr gene on chromosome 1 has been identified in at least 5-15\% of North American and European populations (Schneider et al., 1998). This Mthfr polymorphism is defined as a cytosine to thymine conversion at base pair $677(\mathrm{bp} 677 \mathrm{C} \rightarrow \mathrm{T})$ resulting in an alanine to valine substitution at amino acid 222 (Ala222Val). This encodes a thermoliable enzyme whereby the protein encoded by $677 \mathrm{~T}$ loses its FAD cofactor three times faster than the wildtype protein. Individuals with the Mthfr polymorphism have a significant, but non-fatal, $40 \%$ reduction in enzymatic activity (60\% efficacy) and are associated with hyperhomocysteinemia (Frosst et al., 1995). In fact, epidemiological studies have also reported a strong association between this Mthfr polymorphism and risk for stroke (Kumar et al., 2015; Song et al., 2016). For example, a meta-analysis of 22 case-control studies (4564 ischemic stroke patients and 6701 healthy controls) and identified a significant association between the polymorphism and ischemic stroke (Song et al., 2016). In addition, a different meta-analysis looking at 822 child patients after ischemic stroke and 1,552 control patients found that the Mthfr polymorphism was more common in stroke patients (Sarecka-Hujar et al., 2012). While it is evident that elevated levels of homocysteine and lower folate status attributed to an MTHFR deficiency are associated with increased risk of stroke, another important consideration is whether it also affects stroke outcome.

In addition to risk of stroke, homocysteine and folate status may also a role in the severity of stroke outcome. Both the risk and outcome are usually pooled together because the outcome is generally proportional to the risk. For clarification, these are distinguished such that the risk of stroke represents events or the presence of factors that increase the likelihood of a stroke event to occur whereas stroke outcome is the resulting cascading molecular and functional effects after 
the event has already taken place. The relationship between elevated homocysteine levels and stroke outcome remains controversial. For example, one cross-sectional study using 62 patients has shown that elevated homocysteine levels and reduced folate status were independently associated with brain atrophy, post-stroke, after accounting for known risk factors (Yang et al., 2007) whereas the results of the HOPE 2 trial, which contained 258 stroke patients, found no benefit of B vitamin administration on stroke outcome despite showing a slight reduced risk of stroke (Saposnik et al., 2009). A similar finding was reported in a group of 113 patients such that homocysteine levels do not correlate with the functional outcome of acute ischemic stroke patients based on rehabilitation discharge scores (Mizrahi et al., 2005). Most recently, studies are reporting contradictory findings. One Italian study found that high homocysteine levels upon admission to the stroke unit was a strong predictor of poor functional outcome when discharged (Forti et al., 2016) and these findings were confirmed by others in China (Shi et al., 2015). Interestingly, a different study looking at miRNA recently found that the SNP of the MTHFR variant was associated with both increased risk and functional outcome of ischemic stroke (He et al., 2017). These findings suggest a probable role of homocysteine, folate and folate metabolism in stroke outcome.

Overall, alongside homocysteine, folate metabolism may significantly play a role in cardiovascular disease more so than dietary B-vitamin supplementation. Currently, there are no known methods, transcription factors or other methods that could restore Mthfr gene function however there are transgenic mice that overexpress Mthfr (Celtikci et al., 2008). One approach to understanding relationships between stroke, MTHFR, homocysteine, and folate metabolism is to investigate potential mechanisms using stroke models in genetic animal studies. 


\section{Animal models of stroke}

To study stroke in depth, multiple damage models have been developed and refined for rodents (Fluri et al., 2015). Although rodents are the most commonly used animal, rabbits, gerbils, cats, dogs, pigs and primates have also been used (Traystman, 2003; Alawieh et al., 2016). A damage model is a technique specifically performed on an animal to best mimic the damage that may exist clinically. The most commonly used damage model in stroke research is the medial cerebral artery occlusion (MCAO) model. This procedure involves tying off the medial cerebral artery with surgical thread for an extended period of time ( $30 \mathrm{~min}$ to $1 \mathrm{hr})$ followed by reperfusion (restoration of blood flow). Although this model mimics a natural stroke event effectively, it is a highly invasive procedure and consequently damages a significant yet variable amount of brain tissue (Fluri et al., 2015). This significant loss of tissue is uncharacteristic of a human stroke, therefore making it less than ideal. Besides, this method also has a high mortality rate in experimental animals. The Endothelin-1 (ET-1) model involves the injection of ET-1, a potent vasoconstrictor, to the vasculature via a cannula, creating a stroke-like effect and response at the injection site. This model has been used as a less invasive alternative that also has less sample mortality compared to MCAO however there are also significant consequences. For example, the duration of the drug exposure is difficult to control making results difficult to interpret. Surgically, using this model for subcortical structures, such as the striatum, is not ideal because the insertion of the cannula cannot be done without damaging surrounding tissue to gain access. Other models such as the craniotomy model, where the skull is pierced to expose and clamp the medial cerebral artery, and embolic stroke model, where there is an injection of embolus-prone microspheres into the vasculature, have been considered. These 
models are less so used due to their increased invasiveness and high variability in results, respectively.

An increasingly common approach is the photothrombosis model which induces focal ischemic damage (Watson et al., 1985; Labat-gest and Tomasi, 2013). In this damage model, stereotactic coordinates are precisely targeted with laser irradiation of the intact skull (Figure 2). The mechanism of damage functions such that the intraperitoneally injected photoactive dye, when activated, irradiates brain vasculature, generating free radicals that damage endothelial cells and triggers platelet activation (Fluri et al., 2015; Sommer, 2017). Because this model inflicts direct permanent damage to brain tissue and there is a less visible penumbra, there have been concerns as to whether the photothrombosis model truly mimics human stroke. Photothrombosis has overall shown to be highly reproducible, precise and less invasive than other models. In addition, 15 minutes of laser light exposure is sufficient to cause significant ischemic damage, making it a quick and efficient surgical procedure (Labat-gest and Tomasi, 2013). This damage model for stroke could nonetheless be considered an effective model to study the specific effects and mechanisms of ischemic damage outcome without reperfusion. 


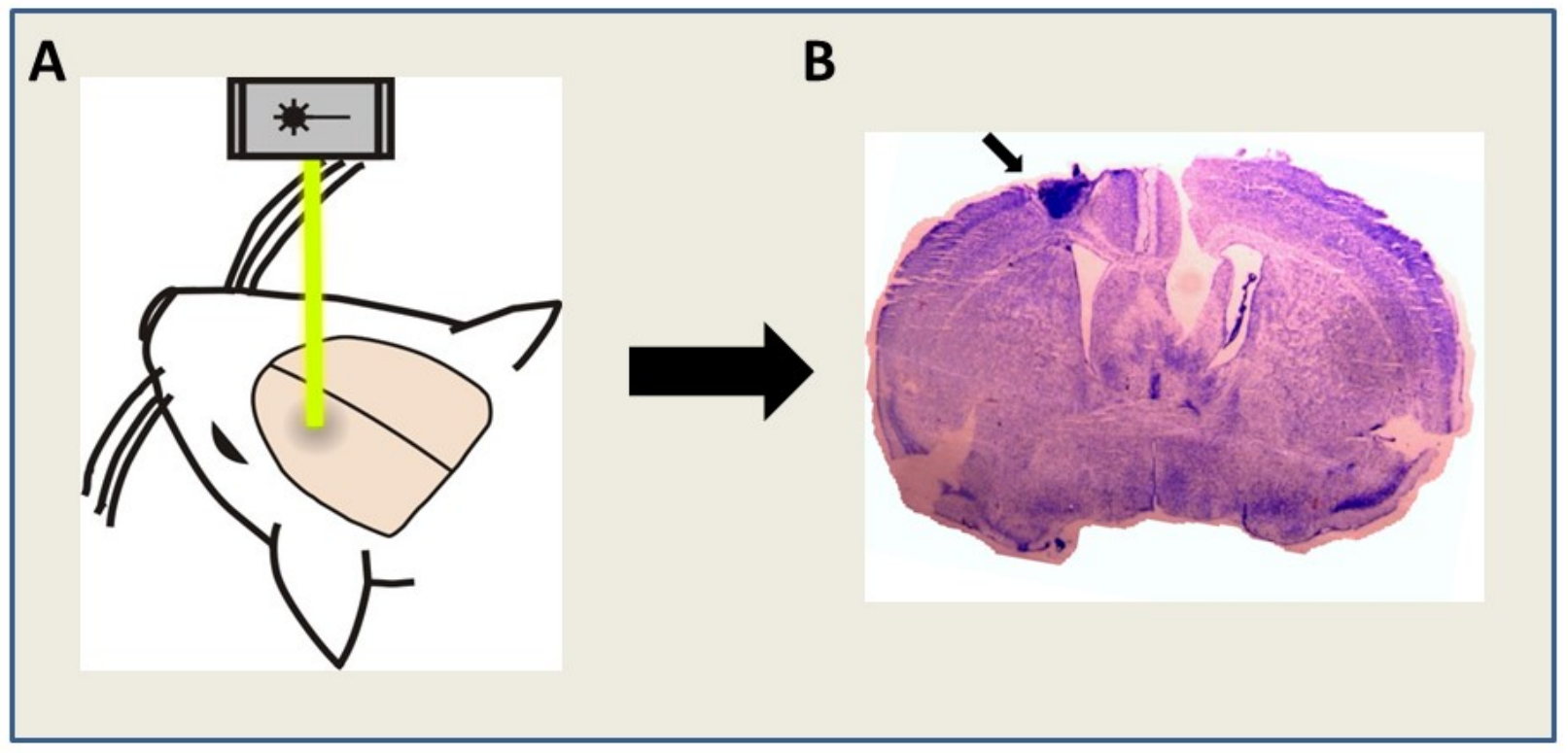

Figure 2. Schematic of photothrombosis-induced ischemic damage in mice. (A) Anesthetized mice were injected intraperitoneally with $10 \mathrm{mg} / \mathrm{kg}$ photoactive Rose Bengal prior to laser exposure. The sensorimotor cortex was exposed to a green $(630 \mathrm{~nm})$ laser light. Image made by Dr. T. S. Kannangara (unpublished). (B) Representative cresyl violet stained brain section with damage to sensorimotor cortex indicated by the black arrow. 


\section{Current animal studies: folate, homocysteine and stroke}

Strong associations between elevated plasma homocysteine levels and reduced folate status, similar to clinical outcomes, have been reported in animal studies. For example, one study reported that C57BL6/J mice exposed to a folate deficient diet had significantly increased plasma homocysteine levels (Troen et al., 2008). In addition, the authors demonstrated a trending increase in the time to reach the escape platform during the Morris Water Maze, a common measure of spatial memory. Interestingly, these behavioural changes corresponded with significant anatomical deficiencies including reduced hippocampal capillary length and microglia number. Significantly elevated plasma homocysteine levels were also observed in a different study using Wistar rats (Kim et al., 2002). Interestingly, the authors also reported increased cytoplasmic swelling and mitochondrial degeneration in the endothelium and cerebrocortical microvasculature wall, further suggesting that elevated plasma homocysteine may be contributing to an increased susceptibility to cellular damage.

Although some studies have investigated relationships between hyperhomocysteinemia and folates, a limited number of experiments using animal models to examine the influence of hyperhomocysteinemia on ischemic damage outcomes have been performed. In general, the underlying mechanism(s) of stroke outcome regardless of homocysteine levels remains unknown, however, increased neuronal cell death via apoptosis (Fan et al., 2014), oxidative stress (Chen et al., 2011) and neuroinflammation via microglial cell activation (Ahmad et al., 2014) may be potential mechanisms through which homocysteine exerts its negative effects. One study reported that after inducing hyperhomocysteinemia by subcutaneous injection and damaging the forebrain with global ischemia, there is an increase in neurodegeneration of hippocampal and cortical neurons compared to controls (Kovalska et al., 2015). A different study 
using Wistar rats reported interesting results with regards to secretory pathway $\mathrm{Ca}^{2+}$-ATPases 1 (SPCA1), which plays an essential role in normal neuronal development, neural migration, and morphogenesis (Pavlovicova et al., 2012). The authors found that hyperhomocysteinemic rats treated with global forebrain ischemic preconditioning (IPC; a process of administrating sublethal short-term ischemia to build tolerance to lethal ischemia) showed elevated SPCA1 mRNA expression compared to both non-IPC hyperhomocysteinemic and non-IPC homocysteine control groups (Pavlovicova et al., 2012). These data suggest that, given the additional cellular stress of reduced SPCA1 expression via hyperhomocysteinemic conditions, ischemic preconditioning showed an increased magnitude of healthy SPCA1 expression, also suggesting that hyperhomocysteinemia may cause an increased cellular vulnerability to ischemic damage. A different study using 129/Sv mice also found that, when exposed to a folate deficient diet, resulting in elevated plasma homocysteine levels, after an MCAO-based ischemic stroke the mice were more susceptible to the damage and had worse functional outcomes compared to controls (Endres et al., 2005). In addition, they reported elevated oxidative DNA damage. Studies have investigated the impact of genetic deficiencies in folate metabolism on neurological function (Troen et al., 2008; Jadavji et al., 2012, 2015a) however no reports have examined the effects of genetic deficiencies in folate metabolism on ischemic damage or stroke.

\section{MTHFR mouse model}

To study the in vivo effects of deficiencies in folate metabolism in the brain, a knockout mouse model for MTHFR has been developed (Chen et al., 2001; Jadavji et al., 2012). Only $M t h f r^{+/+}$and $M t h f r^{+/-}$mice were used. $M t h f r^{-/ /}$knockout do exist but they model an inborn error of metabolism and are severely developmentally delayed (Chen et al., 2001; Lawrance et al., 2011). In brief, heterozygous mice $\left(M t h f r^{+/}\right)$mimic the polymorphism described in humans, having 
elevated plasma levels of homocysteine and decreased MTHFR enzyme activity. Specifically, $M t h \mathrm{fr}^{+/-}$mice have decreased global methylation and have approximately 1.6 fold elevated total plasma homocysteine levels compared to wild-type controls $\left(M t h f r^{+/+}\right)$(Chen et al., 2001). A different study examining the impact of both an MTHFR and dietary folic acid deficiency found that there was a synergistic effect on increased total plasma homocysteine, decreased methylation (as indicated by a lower SAM/SAH ratio) as well as endothelial function (Devlin et al., 2004). Their findings suggested that mice with the MTHFR deficiency were even more so sensitive to impairments in endothelial function and methylation capacity caused by disruptions in folate status than only a dietary folate deficiency in cerebral microvessels. Overall, there appears to be a limited understanding of how a genetic MTHFR deficiency, resulting in elevated levels of homocysteine, impact stroke outcome.

\section{Aim of thesis:}

The aim of this thesis is to investigate the impact of a MTHFR deficiency and resulting increased plasma homocysteine on stroke outcome in a clinically relevant aged mouse model. This was done by assessment of motor behaviour and neurodegeneration after ischemic damage to the sensorimotor cortex. The objectives with corresponding hypotheses are as follows:

Objective 1: To evaluate motor function, after ischemic damage, using a battery of behavioural tests on MTHFR mice.

Hypothesis 1: MTHFR mice have impaired skilled reaching, after ischemic damage, compared to respective shams.

Hypothesis 2: $M t h f r^{+/}$mice have reduced skilled motor function, forepaw use, balance, and coordination, after ischemic damage, compared to wild-type littermate controls. 
Objective 2: To quantify lesion volume and the concentration of plasma homocysteine after ischemic damage in MTHFR mice.

Hypothesis 3: $\mathrm{Mthfr}^{+/}$mice have larger lesion volumes and elevated plasma homocysteine compared to wild-type littermate controls.

Objective 3: To investigate relevant changes in biochemical pathways including oxidative stress, inflammation and apoptosis, after ischemic damage in MTHFR mice.

Hypothesis 4: $M t h f r^{+/}$mice have increased oxidative stress, inflammation and apoptosis, after ischemic damage, compared to wild-type, littermate controls. 


\section{Materials and Methods}

\section{Animals}

All experiments performed in this study were conducted according to the guidelines of the Canadian Council on Animal Care (CCAC) and approved by the Carleton University Animal Care committee. In this study, a total of 33 male MTHFR C57BL/6N mice were used from two cohorts. Mice were aged to 18 months to be reflective of a 65-year-old human (Table 1) with an ad-libitum diet of standard mouse chow. MTHFR deficient $\left(M t h f r^{+/-} \mathrm{n}=17\right)$ mice were raised in standard caging with their littermate wild-type $\left(M t h f r^{+/+}, \mathrm{n}=16\right)$ controls. Prior to experimentation, mild enrichment, including a ladder rung and wooden block, was added to the home cage. 
Table 1. Comparison of mature life history stages in aging between humans and mice. C57BL mice aged 18-24 months old are approximately reflective of human seniors between 56-69 years old. Adapted from Figure 20-3 (Flurkey et al., 2007).

Age Category

Young adult

Middle-aged adult

Senior adult
Human Age (years)

20-30

$36-47$

$56-69$
Mouse Age Equivalent (months)

3-6

10-14

18-24 
Genotype for wild-type $\left(M t h f r^{+/+}\right)$and MTHFR deficient $\left(M t h f r^{+/}\right)$was obtained using polymerize chain reaction (PCR). In brief, DNA was isolated from ear tissue samples. The primers used for PCR were: mmEx3S (5'-GAC GCA GAG GGA AGG AGG CTT CAG-3'), NeoS5 (5'-AGC CTG AAG AAC GAG ATC AGC AGC-3') and mIN3a1 (5'-GAC TAG CTG GCT ATC CTC TCA TCC-3’) (Chen et al., 2001).

\section{Experimental design}

To study the impact of a MTHFR deficiency on neurodegeneration, including both behavioural and molecular changes, an experimental outline has been summarized (Figure 3). After being raised to an aged status ( $\sim 1.5$ years old), mice were then subjected to a battery of behavioural tests to assess motor function and short-term memory. General handling behaviours were observed and weights were measured weekly except for during the single pellet reaching task where weight was monitored daily to be more observant of any potential food restrictioninduced stress. Completing the single pellet reaching task requires approximately 8 weeks prior to ischemic damage because of training as well as testing until achieving peak performance. Ischemic damage via photothrombosis was then performed and mice were given a three day recovery period before post-operational assessment of behaviours. Mice were then euthanized so that brain tissue and blood could be collected for molecular analysis of potential underlying molecular mechanisms. 


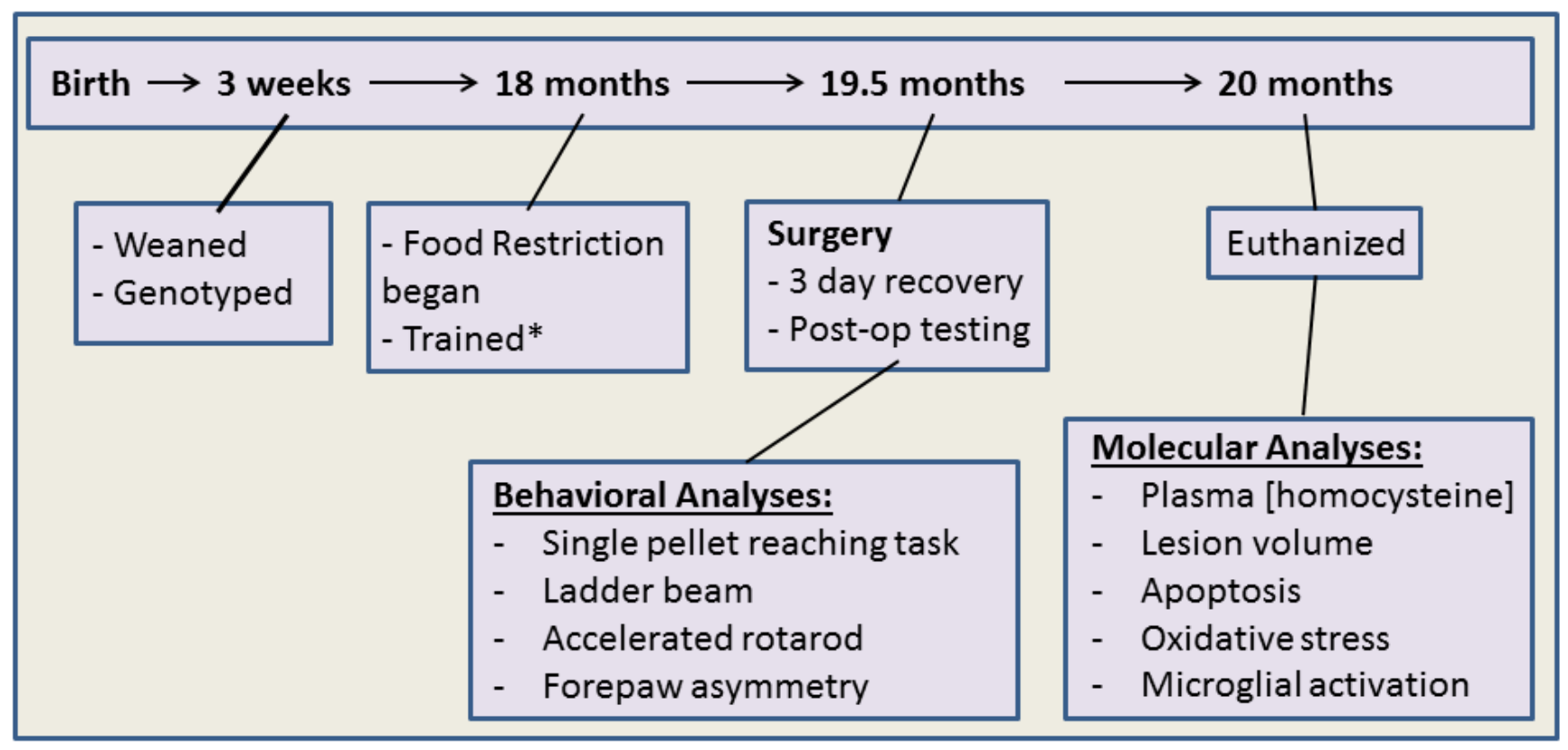

Figure 3. Experimental timeline for the proposed study. The single pellet reaching task was performed daily for 1 month. Rotarod, y-maze, forepaw asymmetry and ladder beam tests were performed once. Susceptibility to damage was examined by analyzing differences between groups post-ischemic damage. 


\section{Photothrombosis}

Using the photothrombosis ischemic damage model, mice were anesthetized with 4-5\% isoflurane in $\mathrm{O}_{2}$. Anesthetized mice had their heads shaved and disinfected while preventing their eyes from drying out with tear gel. Twenty $\mathrm{mg} / \mathrm{kg}$ tramadol and $1 \mathrm{~mL}$ saline was administered subcutaneously. Mice were then transferred to a stereotaxic apparatus (Stoelting) and maintained at 2-2.5\% isoflurane. A heating pad (Harvard Apparatus) was placed under mice and a probe was rectally inserted to maintain a body temperature of $\sim 37^{\circ} \mathrm{C}$. Prior to laser exposure, mice were injected intraperitoneally with $10 \mathrm{mg} / \mathrm{kg}$ photoactive Rose Bengal (Sigma) followed by a 5 minute delay to allow the dye to enter circulation. The skull was then surgically exposed and the sensorimotor cortex was targeted using stereotaxic coordinates $(2 \mathrm{~cm}$ above, mediolateral +0.24 $\mathrm{mm}$ from Bregma). Keeping moist with saline, the skull of the treatment group receiving the ischemic damage (PT group) was exposed to a laser (Beta Electronics, wavelength: $532 \mathrm{~nm}$ ) for 15 minutes (Figure 2). Mice in the Sham treatment group received the same protocol except for laser exposure. For recovery of post-operative pain, $20 \mathrm{mg} / \mathrm{kg}$ tramadol was administered once 6 hours after damage.

\section{Behavioural tasks}

\section{Single pellet reaching task}

The task was performed as previously described (Farr and Whishaw, 2002) to examine skilled forepaw movements. Mice were placed in a $19.5 \mathrm{~cm}$ long x $8 \mathrm{~cm}$ wide x $20 \mathrm{~cm}$ high plexiglass reaching box with a $1 \mathrm{~cm}$ wide vertical slit for reaching out onto plexiglass shelving (Figure 4A). Mice were then trained to approach and extend their forepaw past the slit to obtain $20 \mathrm{mg}$ sugar pellets (Bio-Serv) placed over small divots on the shelving. Mice were acclimated to the plexiglass box by placing them in the box and gradually increasing to 10-minute exposures 
with sugar pellets on the apparatus floor and on the shelf. Sugar pellets were gradually placed further away and decreased in number until reaching was a requirement to obtain a single pellet of food. A pellet was then placed on both the left and right divots so that mice could display a preferred forepaw which was then used for data recording. Motivation required for reaching was achieved by using a dietary restriction of 1-4 g chow per day, administered at least five hours after testing. No testing was done during the three day recovery period after surgery therefore these data points are not included. Both the overall percent reaching success (quantitative) and reaching components (qualitative) were measured. 
A

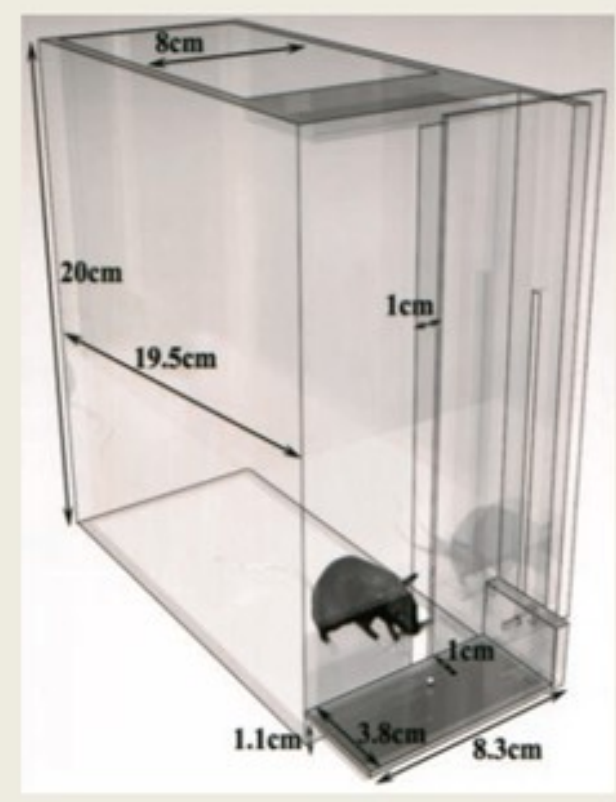

B

$\quad$ Reaching Scoring Scale
I Success
I Attempt (did not touch pellet)
XAttempt (did touch pellet)
口Obtained pellet with tongue
K Knocked Pellet Away
W Walked Away
T Wrong Paw
† Obtained Pellet with Wrong Paw
T Knocked Pellet with Wrong Paw

Figure 4. (A) A graphic representation of the reaching apparatus for the single pellet reaching task in mice (adopted from Farr and Whishaw 2002). (B) The quantitative scoring scale used to determine the percent reaching success rate (made by JK Theoret). 
Quantitative reaching was observed and recorded using a predetermined scale (Figure 4B). Mice were placed in the apparatus and tested until a total of 10 successes was achieved using their preferred forepaw. A success was defined as obtaining and eating the food pellet on the first attempt per reach. Qualitative data involved scoring the quality of 10 specific reaching components previously described (Farr and Whishaw, 2002) and summarized (Table 2). Mice were scored using a three-point system ( 0 being absent, 1 being impaired and 2 being normal) from the principles of the Eshkol-Wachmann Movement Notation (EWMN). Qualitative data was recorded using a digital camera so that frame-by-frame analysis could be done to properly score animals. 
Table 2. Qualitative assessment of the single pellet reaching task in 10 reaching components. Used from Farr and Whishaw (2002). A score of 0 indicated complete impairment and a score of 2 indicated normal behaviour.

\section{Reaching Component Description}

1. Digits to midline The forepaw digits aligned with the body midline

2. Digits semi-flexed The forepaw digits were extended at least slightly outward

3. Elbow discrete The elbow moved in a forward swooping motion

4. Advance straight on The animal was perpendicular to the slit

5. Digits extend Forepaw digits extended as the forelimb moves towards the pellet

6. Arpeggio the paw was placed over the sugar pellet in an arpeggio motion

7. Grasp Digits flexed and closed around the food pellet

8. Supination I The paw with food withdrew by $\sim 90^{\circ}$

9. Supination II The forelimb brought the food to the mouth at $\sim 45^{\circ}$

10. Release The mouth contacted the paw as it releases grasp on the food 


\section{Ladder beam}

The ladder beam task was performed as previously described (Farr et al., 2006) to assess skilled walking movements. Two plexiglass walls $(69.5 \mathrm{~cm}$ x $15 \mathrm{~cm})$, each with holes $20 \mathrm{~mm}$ in diameter and $50 \mathrm{~mm}$ apart located $1 \mathrm{~cm}$ above the bottom, were $5 \mathrm{~cm}$ apart which suited passage of a mouse. Holes were filled with $8 \mathrm{~cm}$ long metal bars in an irregular (random) pattern to prevent learning. The ladder beam apparatus was situated atop two opened standard mouse cages. Data was recorded using a digital camera so that frame-by-frame analysis of movements across the ladder could be obtained. Recorded data was scored using a six-point scale previously described (Metz and Whishaw, 2002; Farr et al., 2006) and summarized (Table 3). The average movement score, number of errors and percent error was calculated ((number of errors/total steps)*100). Any score of two or lower was considered an error. 
Table 3. Qualitative assessment of the ladder beam task. Used from Farr et al., (2006). A score of 2 or lower was considered an error.

\section{Score Description}

$0 \quad$ A total miss of a rung and causes the body of the animal to fall.

1 The paw contacts the rung but then slipped causing the body of animal to fall.

2 The paw contacts the rung but then slipped slightly but the animal kept moving.

3 The paw contacts one rung (not bearing weight) but then quickly switched to another rung or the wall.

4 The paw approaches a rung (not touching it) then places it on another rung or places the paw on a rung but then repositions it on that same rung.

5 The paw is partially placed on a rung such as only some or all digit tips.

$6 \quad$ A correct placement. 


\section{Accelerated rotarod}

A standard accelerating rotarod apparatus (Omnitech Electronic Inc.) was used to measure walking movements and balance previously described (Balkaya et al., 2013; Jadavji et al., 2015a). $30 \mathrm{~cm}$ above the ground, mice were then placed on a rotating cylinder $3 \mathrm{~cm}$ in diameter and $6 \mathrm{~cm}$ wide such that the speed gradually increased from 4 to $60 \mathrm{rpm}$ over 8 minutes. When mice fall off the rotarod, a digital sensor records the latency, in seconds, to fall off the rotarod cylinder. An average of three trials per mouse was taken with an inter trial interval of five minutes.

\section{Forepaw asymmetry}

To measure spontaneous forelimb use, mice were placed in a $19 \mathrm{~cm}$ high, $14 \mathrm{~cm}$ diameter cylinder and the placement of their forepaws on the beaker wall during natural exploratory rearing behaviours was recorded using a digital camera for frame-by-frame analysis (Theoret et al., 2015). A total of 10 rears were recorded. During a rear, the first forepaw placement to touch the beaker wall was recorded as ipsilateral, contralateral (to damage) or both. The final score for one mouse was calculated as: (sum of non-impaired forepaw placements - sum of impaired forepaw placements) / total forepaw placements (impaired, non-impaired and both). Therefore, a positive score indicated preferences for the non-impaired forepaw, suggesting impairment, and a negative score indicated an impaired forepaw placement.

\section{Plasma homocysteine concentration}

At time of euthanization, cardiac blood samples were collected. Plasma samples were prepared according to manufacturer's instructions for Advia Centaur Homocysteine kit and measured using Centaur XP platform (Siemen’s Canada). 


\section{Lesion volume}

Brain tissue was sectioned on a cryostat (Thermo Fisher Scientific) at $30 \mu \mathrm{m}$ and were then mounted on slides in serial order. Each animal had six slides that contained brain sections spanning the entire damage area. Two series was used for basic neuronal structure analysis via cresyl violet (Sigma) to quantify the size of the ischemic infarct. As shown in Figure 2B, damaged tissue clearly stains a darker shade of purple compared to undamaged tissue. ImageJ (NIH) software was used to quantify lesion volume by measuring the area of damaged tissue. Each animal had a minimum of four sections that were used for quantification. 


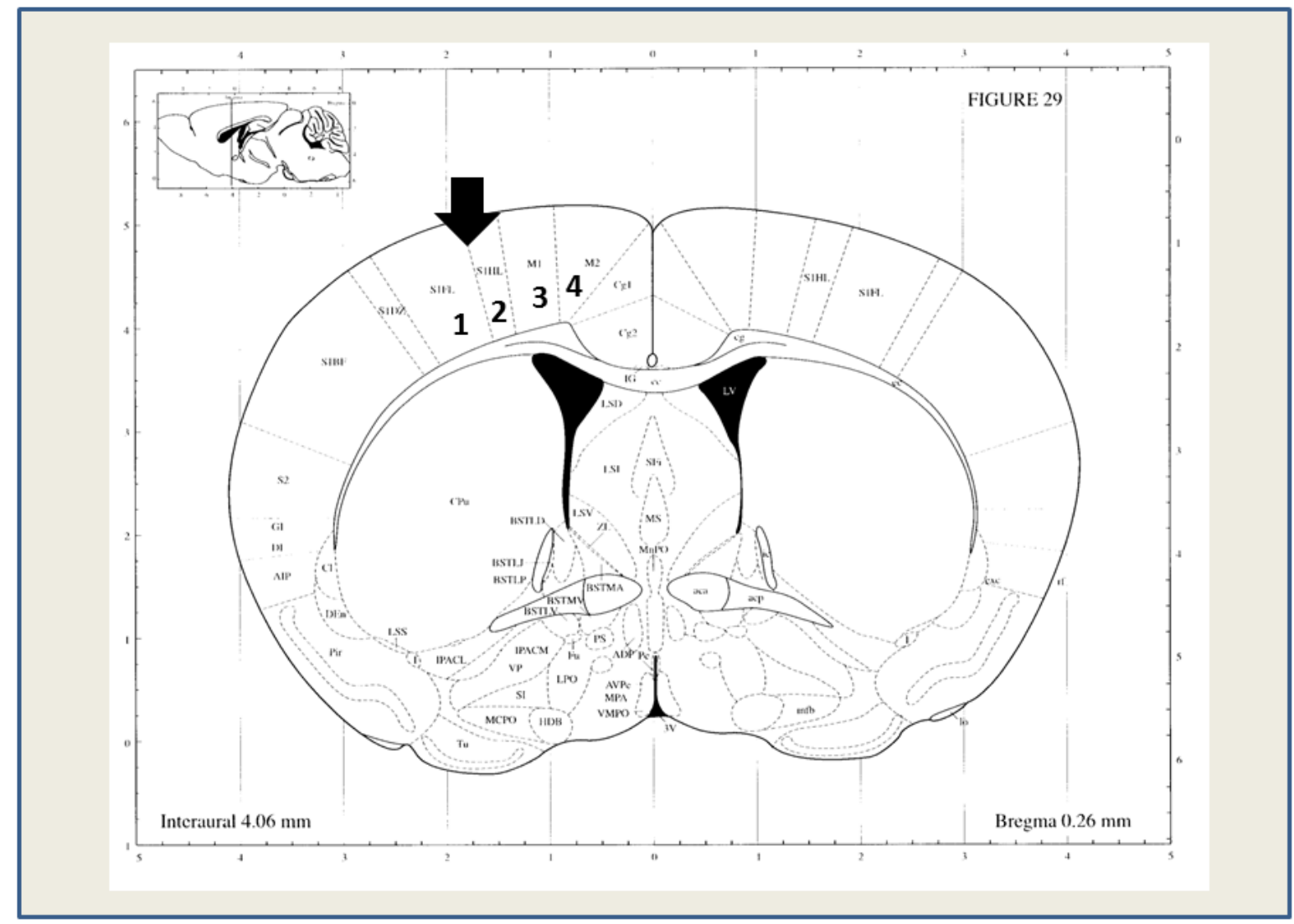

Figure 5. Coronal slice of a mouse brain highlighting important cortical regions (1) Somatosensory cortex, forelimb region (S1FL), (2) Somatosensory cortex, hindlimb region (S1HL), (3) Primary Motor cortex (M1) and (4) Secondary Motor cortex (M2). Original obtained from Paxinos and Franklin, (2001). The black arrow within the somatosensory cortical regions was the area of interest for ischemic damage. 


\section{Immunofluorescence}

Brain tissue was used for immunofluorescence analysis to assess molecular mechanisms. Staining was performed on brain tissue to investigate potential mechanisms. The following primary antibodies were used, Nuclear factor-like 2 (Nrf2) (1:100, Santa Cruz Biotechnology) Superoxide dismutase 2 (SOD2) (1:100, Life Technologies) to measure antioxidant activity; Ionized calcium-binding adapter molecule 1 (Iba1) (1:100, AbCam), Cluster of Differentiation 68 (CD68) (1:500, BioRad) to assess inflammation, p53 (1:100, Santa Cruz Biotechnology) to measure DNA damage and active caspase-3 (1:100, Cell Signalling Technologies) to measure apoptosis. All brain sections were stained with NeuN (1:200, AbCam), a marker for neuronal nuclei. Primary antibodies were diluted in $0.5 \%$ Triton $\mathrm{X}$ and incubated with brain tissue overnight at $4{ }^{\circ} \mathrm{C}$. The following day, brain sections were incubated in Alexa Fluor 488 or 555 (Cell Signalling Technologies) secondary antibodies then were incubated at room temperature for 2 hours and then stained with 4', 6-diamidino-2-phenylindole (DAPI) (1:1000). Staining was visualized using a microscope (Zeiss) and all images were collected at the magnification of $40 \mathrm{X}$. For cell count analysis, p53 positive cells were co-localized with DAPI, active caspase-3, Nrf2 as well as SOD2 positive cells were co-localized with NeuN, respectively, and Iba1 positive cells were co-localized with CD68. A positive cell was indicated by co-localization of the antibodies of interest located within a defined cell. Cells were distinguished from debris by identifying a clear cell shape and intact nuclei (indicated by DAPI or NeuN) under the microscope. All cell counts were conducted by two individuals blinded to treatment groups. The number of positive cells were counted in three brain sections per animal. For each section, three fields were analyzed. The number of positive cells were averaged for each animal. 


\section{Statistical analysis}

Both IBM SPSS (Ver 21) and GraphPad Prism 7 software was used to investigate differences between genotypes $\left(\mathrm{Mthfr}^{+/+}\right.$and $\left.M t h f r^{+/}\right)$and treatment groups (Sham vs. PT) after ischemic damage. The single pellet reaching task was analyzed using two-way repeated measures analysis of variance (ANOVA). Single pellet reaching data from $\mathrm{Mthfr}^{+/+}$and $\mathrm{Mthfr}^{+/-}$ mice was analyzed separately to determine interactions and main effects of treatment and time for each genotype. Two-way ANOVA analysis was performed when comparing the average measurement of both genotype and treatment group for the ladder beam, accelerated rotarod, forepaw asymmetry and plasma homocysteine concentration. Main effects of two-way ANOVAs were followed up with Tukey's post-hoc test to adjust for multiple comparisons. Unpaired t-tests were performed on single factor data such as lesion volume and immunofluorescent staining between genotypes. All data is presented as means \pm standard error of the mean (SEM). Statistical tests were performed using an alpha of 0.05 . 


\section{Results}

\section{Skilled reaching: single pellet reaching task}

Reaching success

Daily reaching success prior to damage was approximately $25 \%$. After ischemic damage, $M t h f r^{+/+}$(Figure 6A; $\mathrm{F}_{(1,13)}=6.04, \mathrm{p}<0.05$, treatment effect) and $M t h f r^{+-}$(Figure 6B; $\mathrm{F}_{(1,16)}=$ 27.94, $\mathrm{p}<0.001$, treatment effect) mice demonstrated a reduction in percent reaching success compared to shams for up to five weeks after damage. 

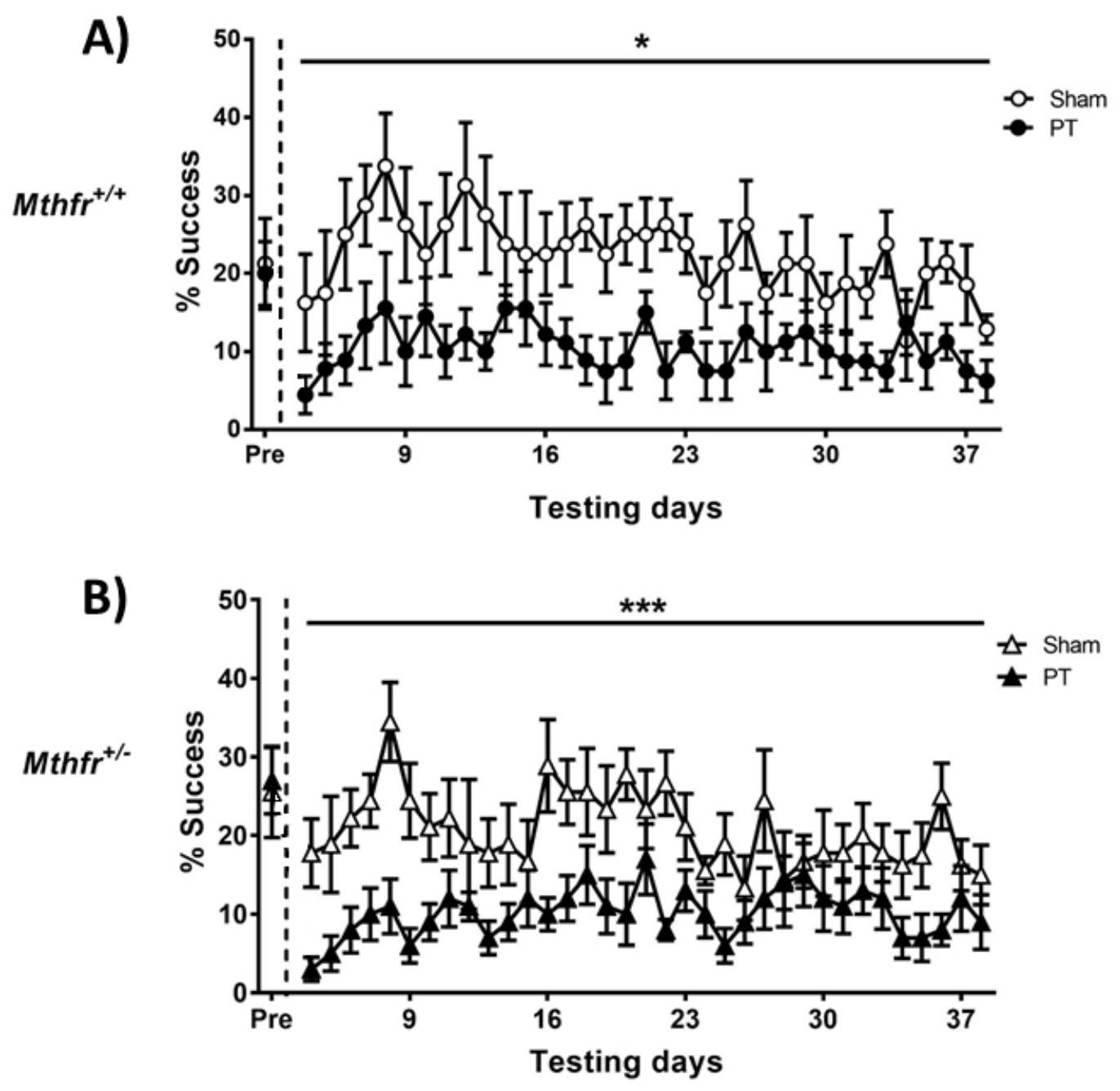

Figure 6. Quantitative assessment of the single pellet reaching task before and after photothrombosis (PT) damage in aged (A) $\mathrm{Mthfr}^{+/+}$and (B) $\mathrm{Mthfr}^{+/}$mice. The data represents means \pm SEM of 8-10 mice per group. ${ }^{*} p<0.05, * * * p<0.001$, treatment effect. The vertical dashed line denotes the day when animals underwent PT damage. 


\section{Reaching score}

A single reach was split into 10 components enabling qualitative analysis of skilled motor function (Farr and Whishaw, 2002). Five weeks after damage there were no difference between $M t h f r^{+/+}$PT and sham mice (Figure 7A; $\left.\mathrm{F}_{(1,14)}=3.71, \mathrm{p}>0.05\right)$. However, $M t h f r^{+/-}$PT showed impairment as a result of damage (Figure 7B; $\mathrm{F}_{(1,15)}=14.01, \mathrm{p}<0.01$, treatment effect). There were no differences between the reaching components within $M t h f r^{+-}$PT and sham groups $(\mathrm{p}>0.05)$. 
A)

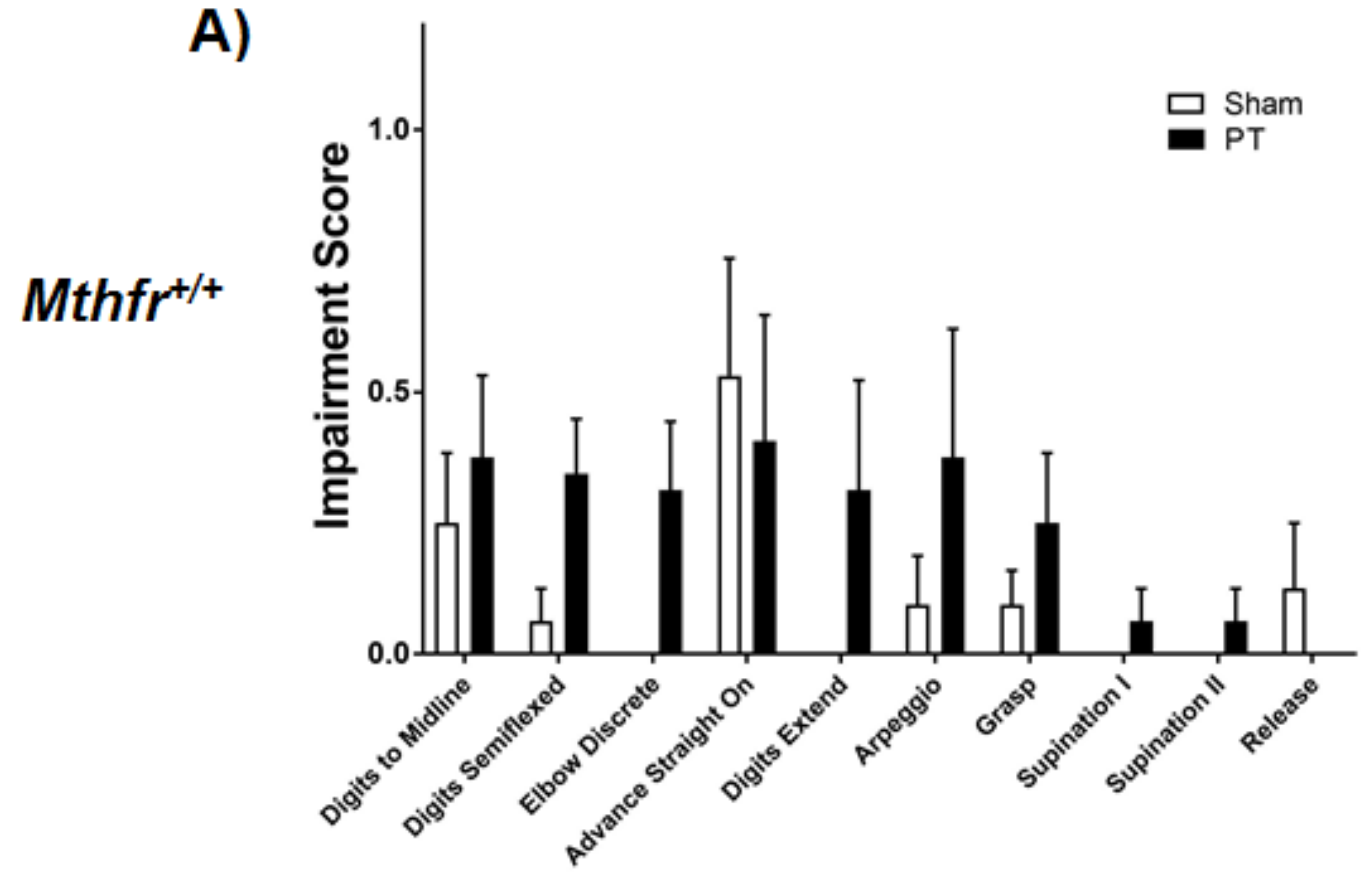

\section{Reaching component}

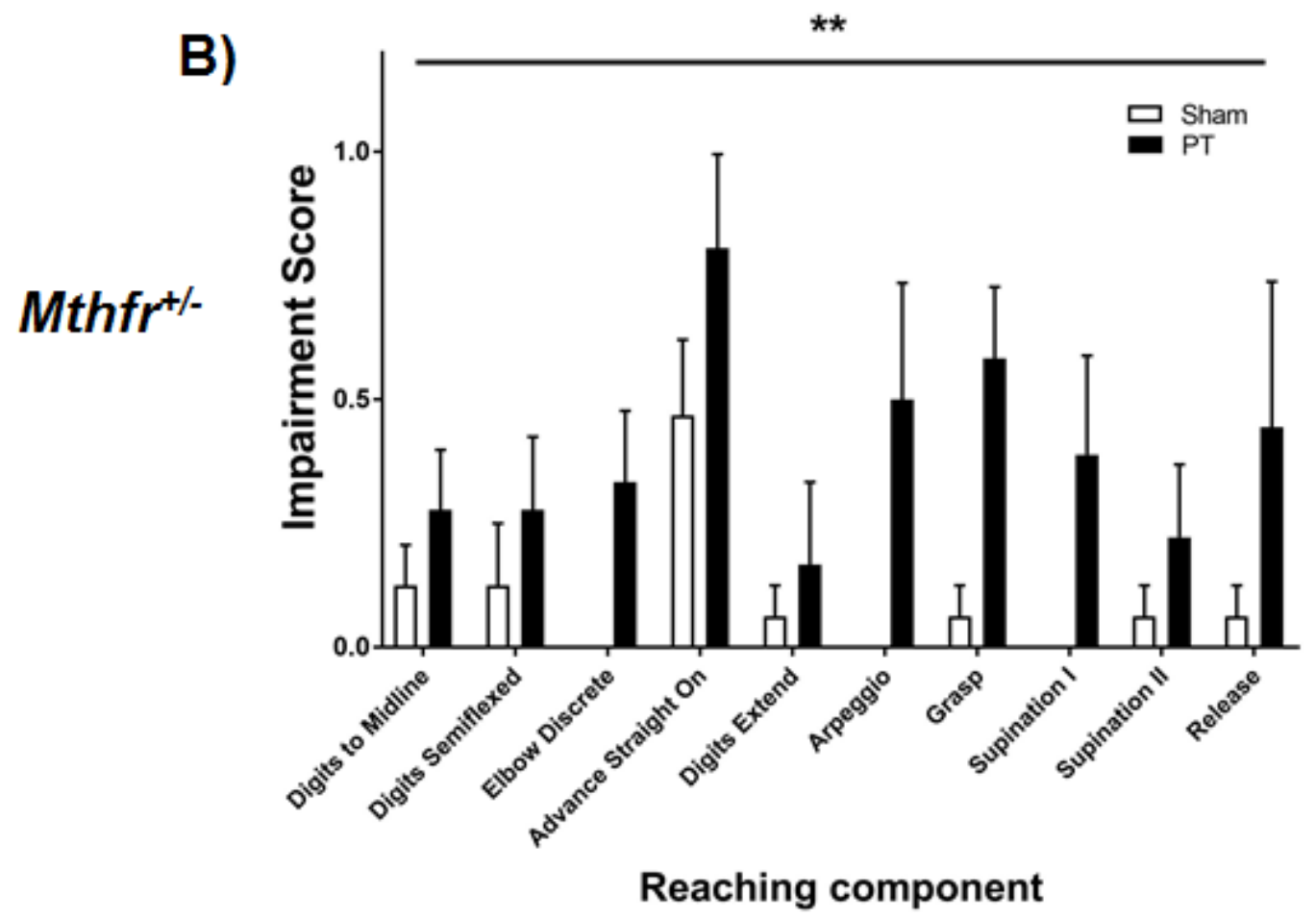

Figure 7. Qualitative analysis of the single pellet reaching task after PT in aged (A) $\mathrm{Mthfr}^{+/+}$ and (B) $\mathrm{Mthfr}^{+/}$mice. The data represents means \pm SEM of 8-10 aged mice per group. $* * \mathrm{p}<0.01$, treatment effect. 


\section{Skilled walking: ladder beam}

Movement score

As animals walked across the ladder beam for the chronic time point after ischemic damage, there was an interaction between genotype and treatment for impairments contralateral to the side of the brain with ischemic damage (Figure 8A; $\mathrm{F}_{(1,28)}=4.31, \mathrm{p}<0.05$ ). There was no difference in the ipsilateral side between treatment groups (Figure 8B; $\mathrm{F}_{(1,29)}=0.11, \mathrm{p}>0.05$ ).

\section{Percent error}

After unilateral ischemic damage via PT, both $M t h f r^{+/+}$and $M t h f r^{+/-}$mice show an increased number of errors made when crossing the ladder beam but only in the contralateral side (Figure 8C; Contralateral, $\mathrm{F}_{(1,29)}=14.40, \mathrm{p}<0.05$, treatment effect). There were no difference on the ipsilateral side (Figure 8D; $\left.\mathrm{F}_{(1,28)}=0.58, \mathrm{p}>0.05\right)$. 
A)

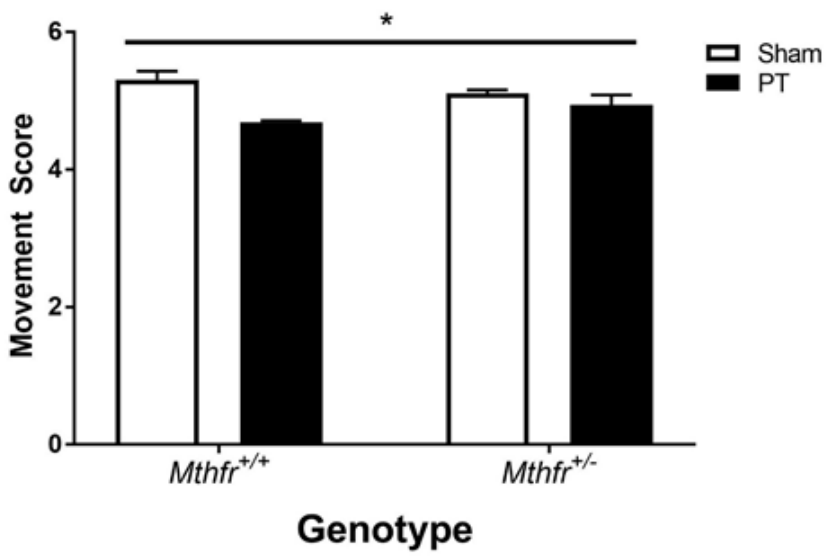

C)

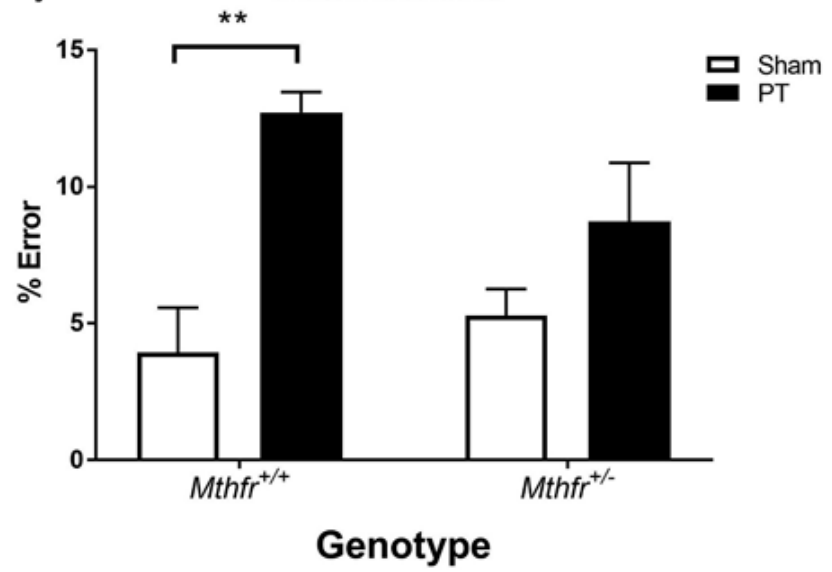

B) Ipsilateral

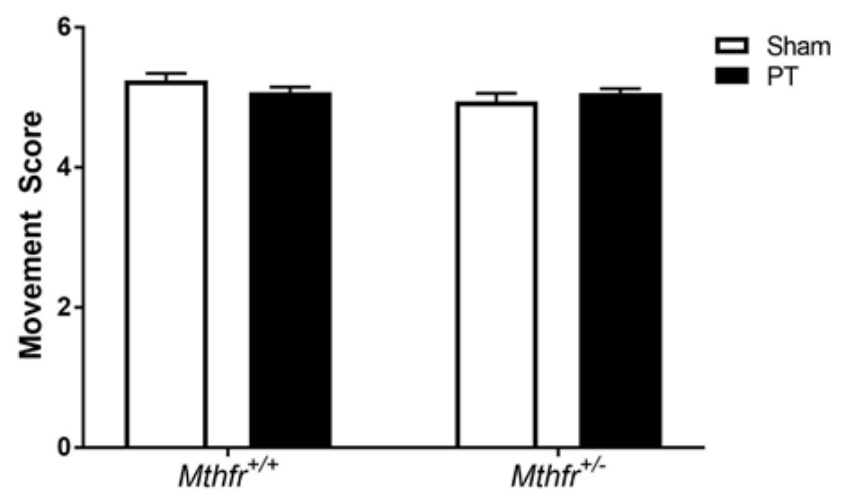

Genotype

D)

Ipsilateral

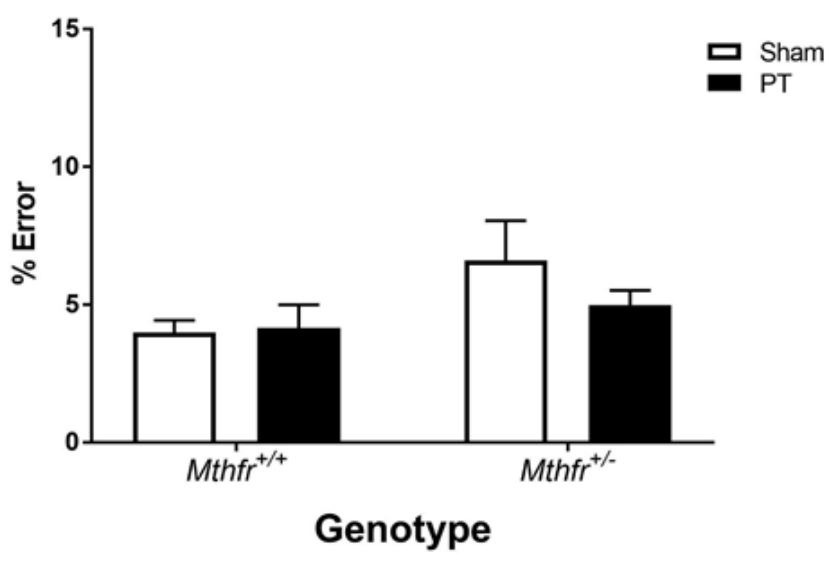

Figure 8. Assessment of skilled motor function on the ladder beam walking task in aged $M t h f r^{+/+}$and $M t h f r^{+/-}$mice. Movement scores of $M t h f r^{+/+}$and $M t h f r^{+/-}$mice (A) contralateral and (B) ipsilateral to ischemic damage. Percent error of $M t h f r^{+/+}$and $M t h f r^{+/-}$mice (C) contralateral and (D) ipsilateral to ischemic damage while crossing the ladder beam. Data represents mean \pm SEM of 8-10 mice per group. ${ }^{*} p<0.05$ genotype and treatment interaction, $* * \mathrm{p}<0.01$ treatment effect, Tukey's pairwise comparison. 


\section{Accelerated rotarod}

Five weeks after ischemic damage, balance and coordination in $M t h f r^{+/}$and $M t h f r^{+/+}$ mice were measured. There were no differences in the time required for mice to fall off the accelerated rotarod between treatment groups nor genotypes (Figure 9; $\mathrm{F}_{(1,27)}=0.89, \mathrm{p}>0.05$, treatment effect; $F_{(1,27)}=0.19, p>0.05$, genotype effect) and there was no interaction (Figure 9; $\left.F_{(1,27)}=0.70, p>0.05\right)$. 


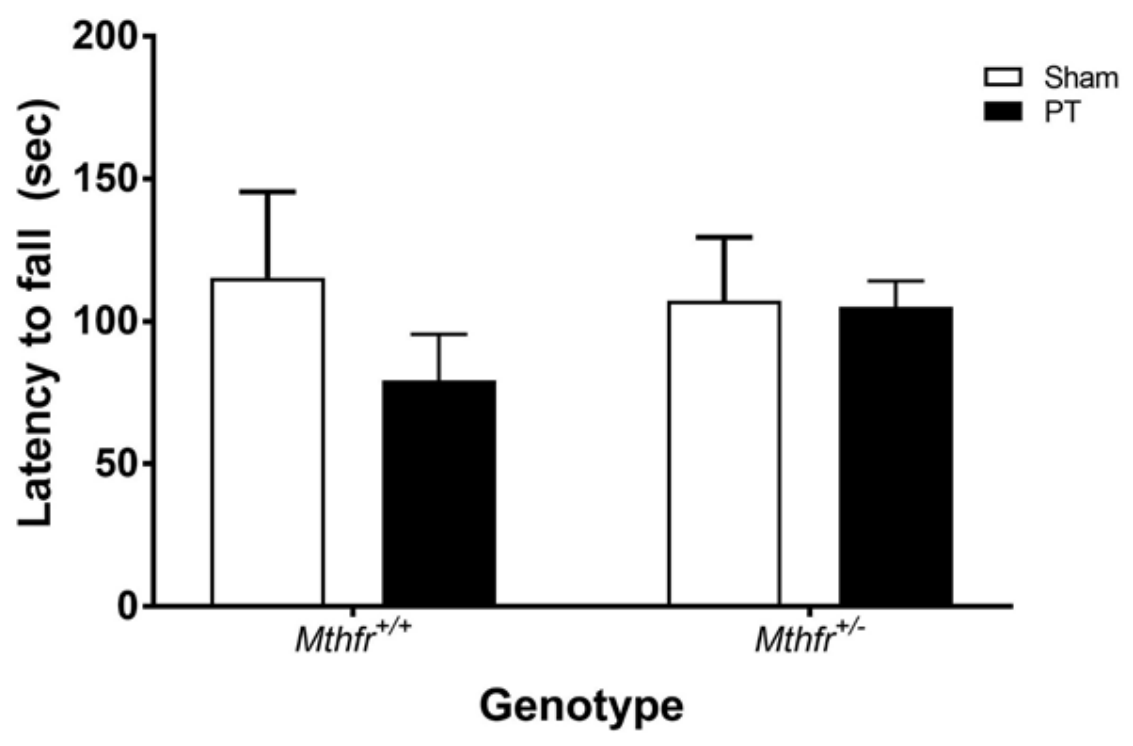

Figure 9. Assessment of balance and coordination in aged $\mathrm{Mthfr}^{+/+}$and $\mathrm{Mthfr}^{+/-}$mice by the accelerated rotarod. Data are mean \pm SEM in 8-10 mice per group. 


\section{Forepaw asymmetry}

The forepaw asymmetry task evaluated forepaw preference through natural rearing behaviours. A positive score indicated favoured use of the ipsilateral paw and a negative score indicates favoured use of the contralateral paw. Five weeks after ischemic damage, there were no differences in index scores between $M t h f r^{+/+}$and $M t h f r^{+/-}$mice (Figure 10; $\left.\mathfrak{t}_{(16)}=1.93, \mathrm{p}>0.05\right)$ and thus no differences in paw preference during natural rearing behaviours. 


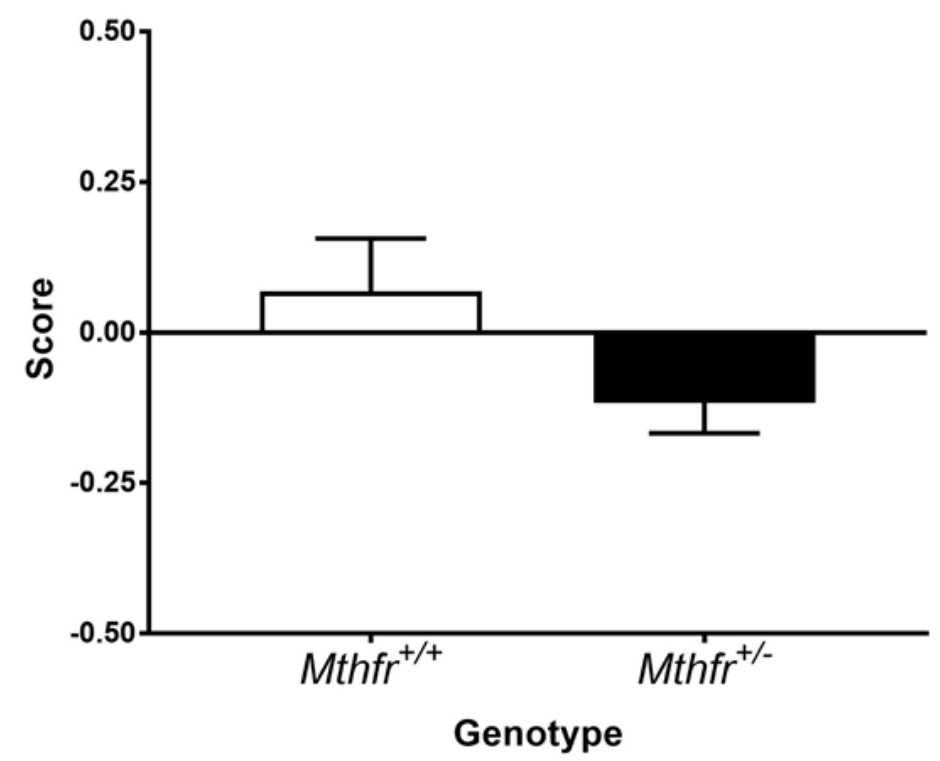

Figure 10. Forepaw asymmetry scores of motor function after unilateral ischemic damage in aged $M t h f r^{+/+}$and $M t h f r^{+/-}$mice. Data are mean \pm SEM in 8-10 mice per group. 


\section{Plasma homocysteine concentration}

Homocysteine concentration was measured in plasma from MTHFR mice. In aged $M t h f r^{+/}$mice, plasma homocysteine levels were elevated compared to $M t h f r^{+/+}$regardless of unilateral ischemic damage to the sensorimotor cortex (Figure 11; $\mathrm{F}_{(1,30)}=5.73, \mathrm{p}<0.05$, genotype effect). 


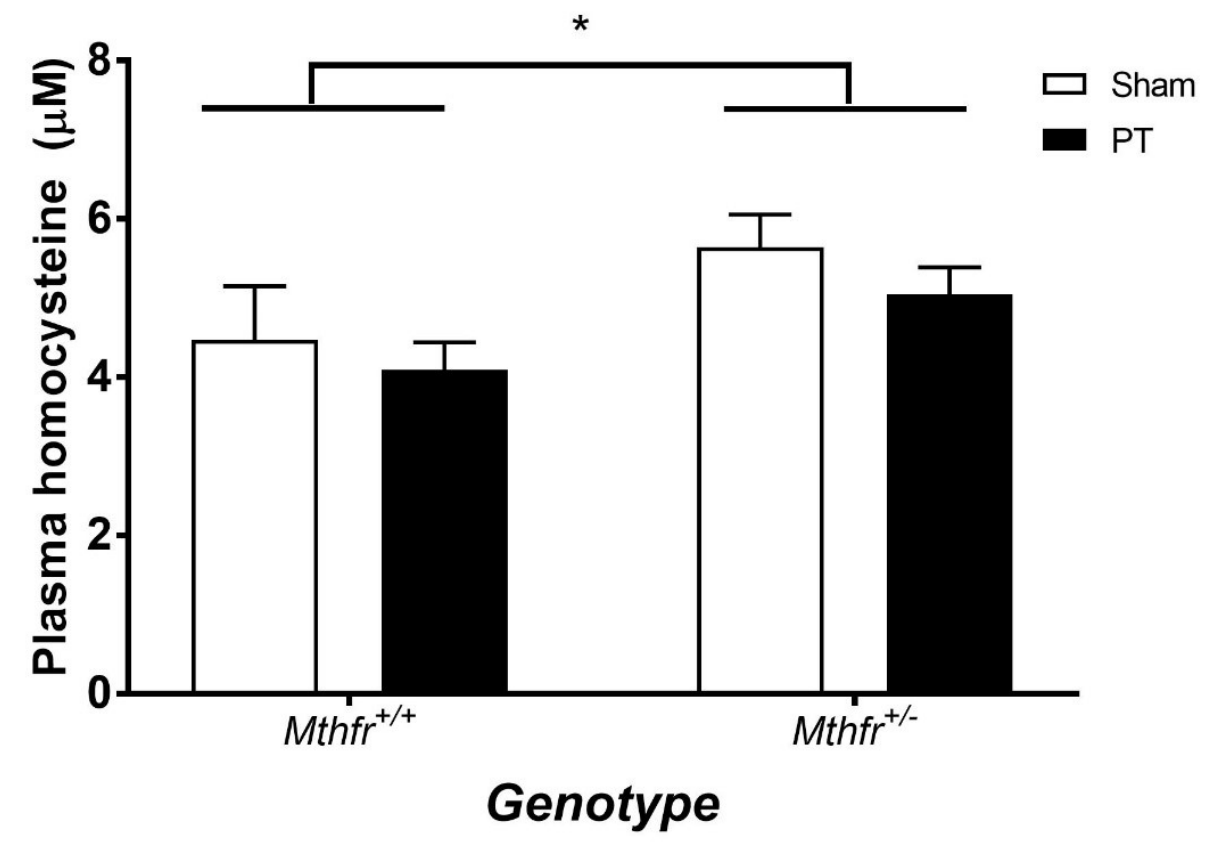

Figure 11. Plasma homocysteine concentrations $(\mu \mathrm{M})$ in aged $M t h f r^{+/+}$and $M t h f r^{+/-}$mice. Data are mean \pm SEM of 8-10 mice per group. ${ }^{*} p<0.05$, genotype effect. 


\section{Lesion volume}

The size of the infarct caused by photothrombosis was quantified in brain tissue stained with a cresyl violet stain (representative images in Figure 12A). After ischemic damage, there were no differences in lesion volume between aged $M t h f r^{+/+}$and $M t h f r^{+/-}$mice (Figure 12B; $\mathfrak{t}_{(15)}$ $=0.31, \mathrm{p}>0.05)$. 

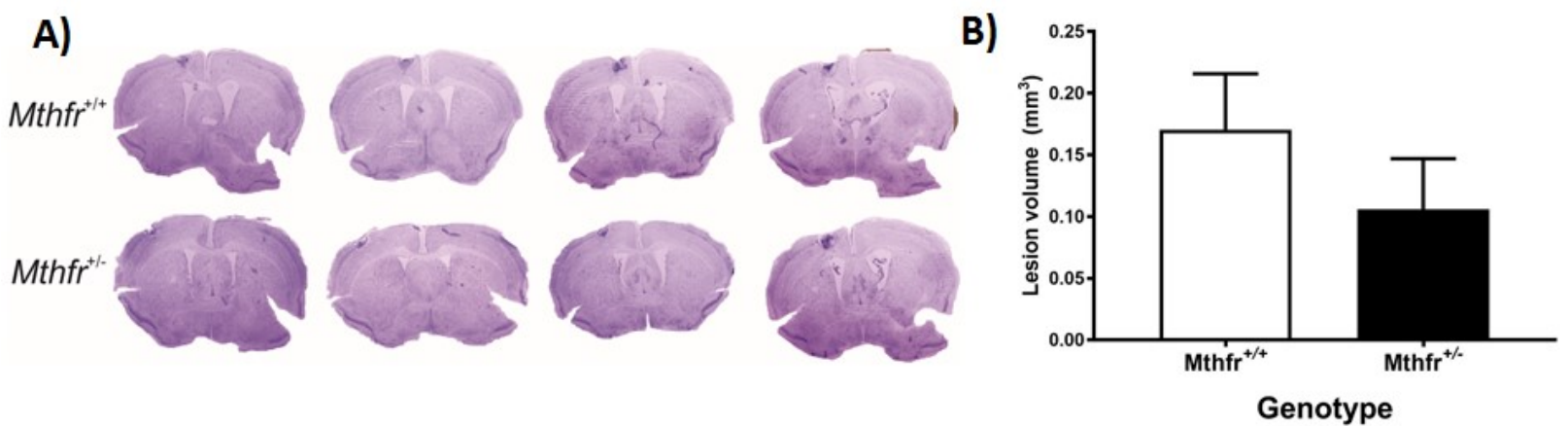

Figure 12. Assessment of the lesion volume from unilateral ischemic damage to the sensorimotor cortex in aged $\mathrm{Mthfr}^{+/+}$and $M t h \mathrm{fr}^{+/-}$mice. (A) Representative cresyl violet stained brain sections from $\mathrm{Mthfr}^{+/+}$and $M t h f r^{+/}$mice. (B) quantification of lesion volume. Data are mean $\pm \mathrm{SEM}$ of 8-10 mice per group. 


\section{Immunofluorescence}

Apoptosis: Active caspase-3

Immunofluorescence of active caspase-3 was examined to quantify the degree of neuronal apoptosis at the damage site which was determined by positive co-localization of activated caspase-3 and neuronal marker NeuN in $M t h f r^{+/+}$and $M t h f r^{+/-}$mice (representative images shown in Figure 13A and 13B). After ischemic damage, $M t h \mathrm{fr}^{+/-}$demonstrated increased active caspase-3 expression compared to $M t h f r^{+/+}$mice (Figure 13C; $\mathrm{t}_{(9)}=3.01 ; \mathrm{p}<0.05$, unpaired t-test). 

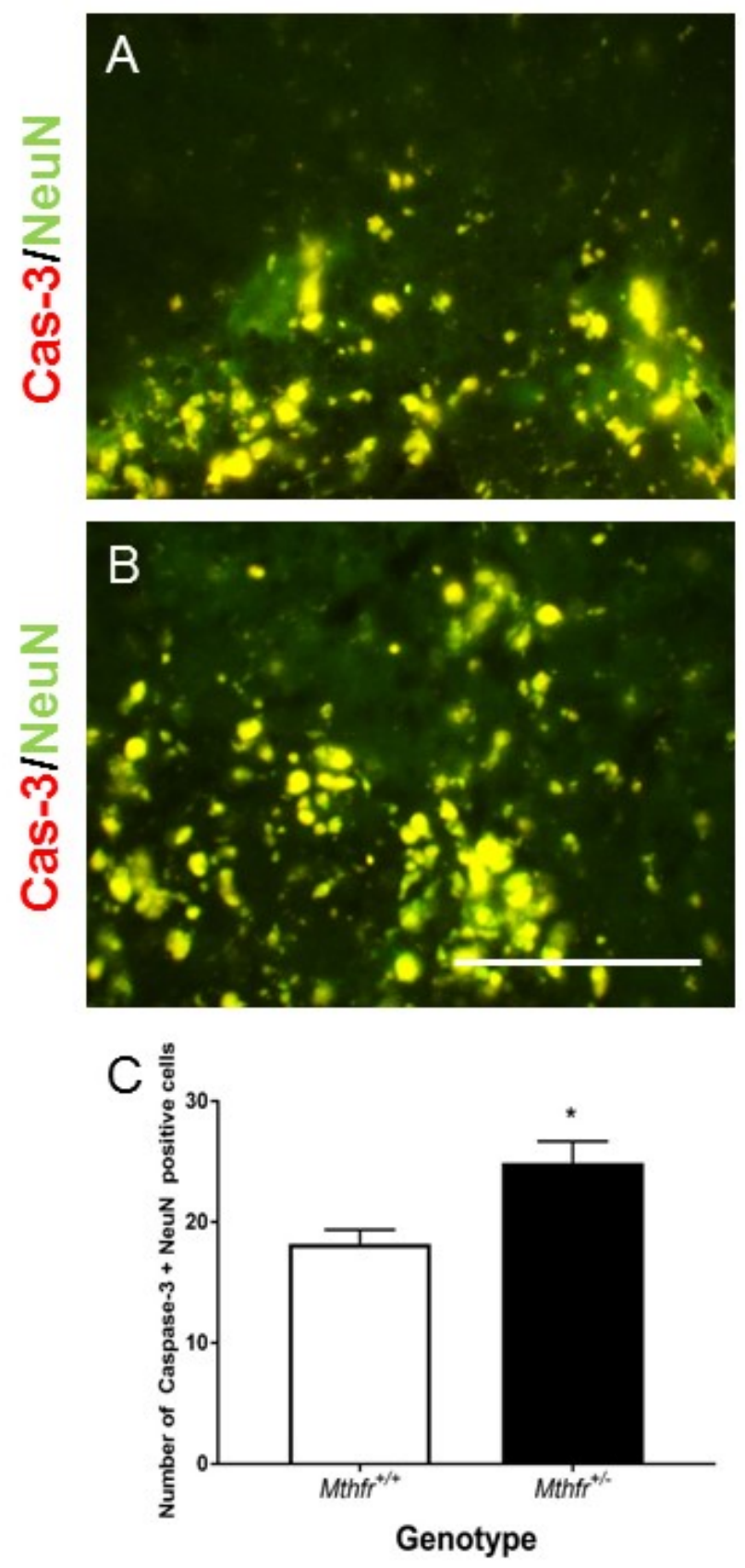

Figure 13. Representative immunofluorescence images of active caspase-3, NeuN and DAPI staining in aged (A) $M t h f r^{+/+}$and (B) $M t h f r^{+/-}$mice. (C) The number of active caspase-3 positive cells co-localized with NeuN after ischemic damage. Data are expressed as mean \pm SEM in 5-6 mice per group. ${ }^{*} \mathrm{p}<0.05$, unpaired t-test, $M t h f r^{+/+}$vs. $M t h f r^{+/}$. Scale bar $=100$ $\mu \mathrm{m}$. 
DNA damage: $p 53$

Immunofluorescence of p53 was also done to assess DNA damage and potentially apoptosis activity. After ischemic damage, there are no differences in the expression of p53 between aged $\mathrm{Mthfr}^{+/+}$and $\mathrm{Mthfr}{ }^{+/}$mice (representative staining shown in Figure 14A and 14B), indicated by co-localization of nuclear $\mathrm{p} 53$ and DAPI at the damage site (Figure 14C; $\mathbf{t}_{(9)}=0.30$, $\mathrm{p}>0.05)$. 

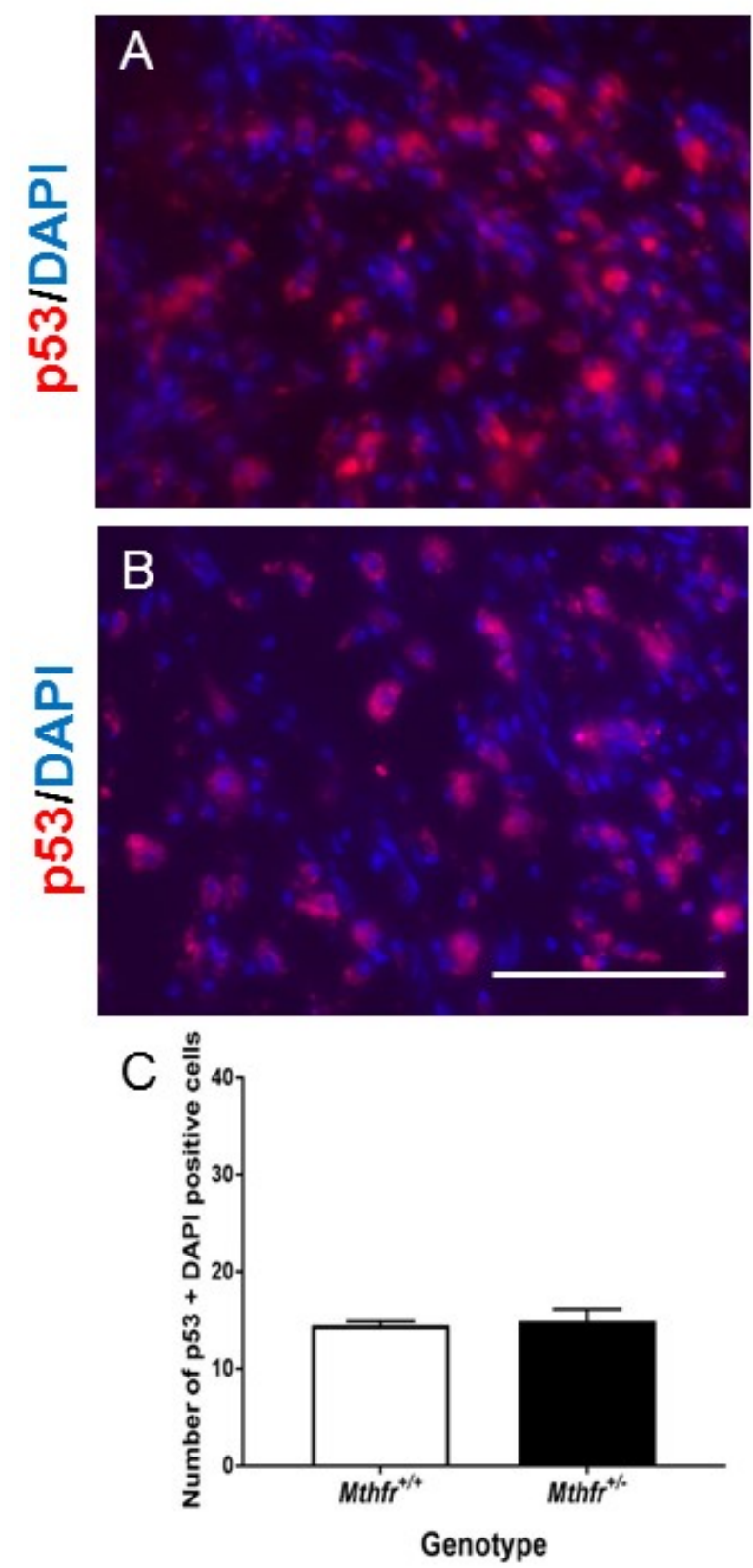

Figure 14. Representative immunofluorescence images of p53 and DAPI in aged (A) $M t h f r^{+/+}$and (B) $M t h f r^{+-}$mice after ischemic damage. (C) The number of p53 positive cells co-localized with DAPI. Data are expressed as mean \pm SEM in 5-6 mice per group. Scale bar $=100 \mu \mathrm{m}$. 
Antioxidant activity: Nrf2

The role of antioxidant activity was examined to understand its role in ischemic damage of MTHFR deficient mice. The antioxidant transcription factor Nrf2 was used as a marker for the regulation of antioxidative proteins as well as the overall oxidative stress response (Sandberg et al., 2014). There was no significant difference in Nrf2 expression in aged Mthfrr ${ }^{+/-}$mice compared to $\mathrm{Mthfr}^{+/+}$in neurons (representative images shown in Figure 15A and 15B). This was indicated by co-localization of Nrf2 with neuronal nuclei marker, NeuN (Figure 15C; $\left.\mathrm{t}_{(4)}=0.19, \mathrm{p}>0.05\right)$. 

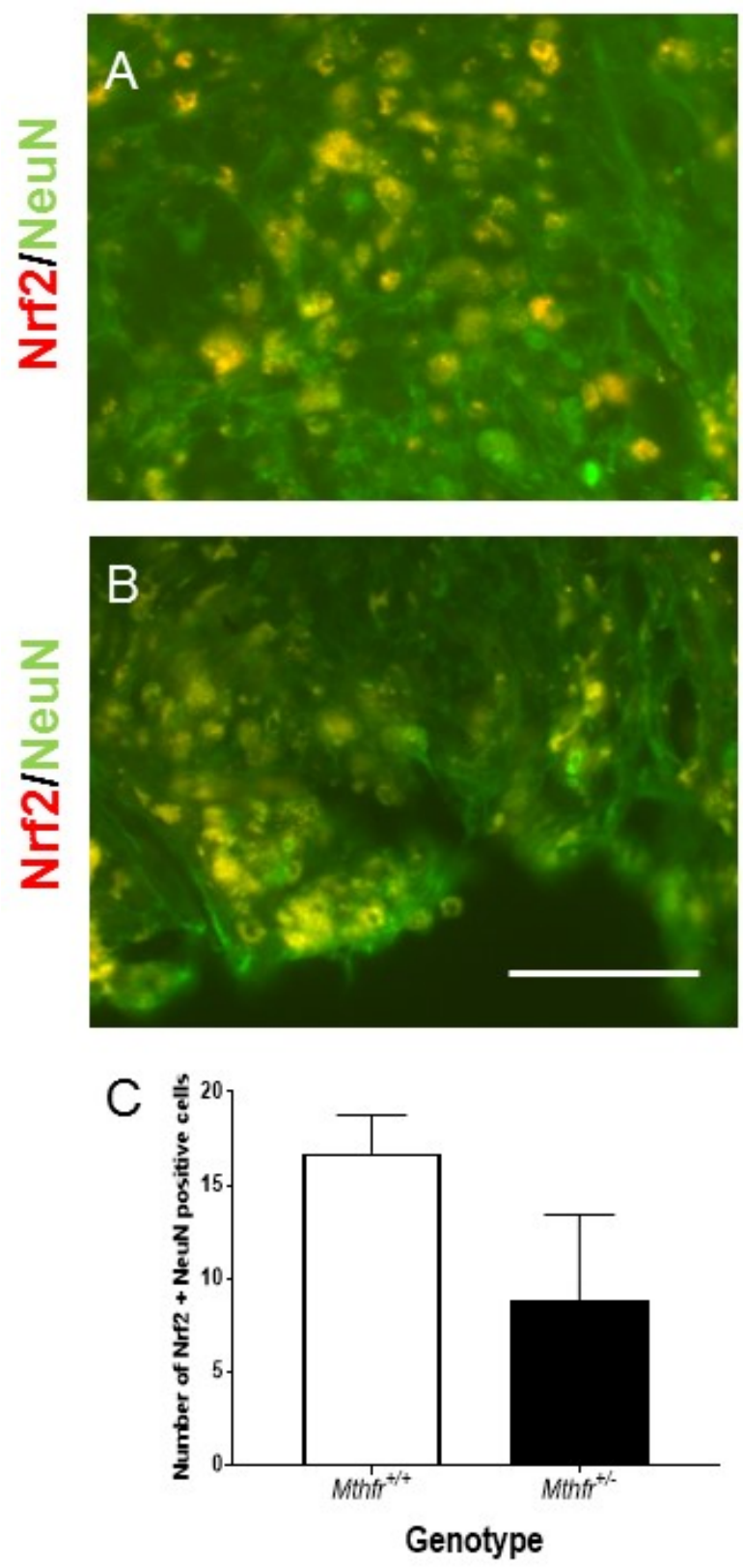

Figure 15._Representative immunofluorescence images of Nrf2 and NeuN staining in aged (A) $M t h f r^{+/+}$and (B) $M t h f r^{+/}$mice after ischemic damage. Scale bar $=100 \mu \mathrm{m}$. (C) The number of Nrf2 positive cells co-localized with NeuN. Data are expressed as mean $\pm \mathrm{SEM}$ in 3 mice per group. 
Antioxidant activity: SOD2

Superoxide dismutase (SOD2) has a protective role after ischemic damage (Chen et al., 2011), therefore SOD2 activity was also examined to evaluate antioxidant enzyme expression after ischemic damage in aged MTHFR deficient mice (representative staining images are shown in Figure 16A and B). NeuN labeled neurons were positively co-localized with SOD2, but there was no statistically significant difference between $M t h f r^{+/}$and $M t h f r^{+/+}$mice (Figure 16C; $\left.\mathrm{t}_{(9)}=1.97, \mathrm{p}>0.05\right)$. 

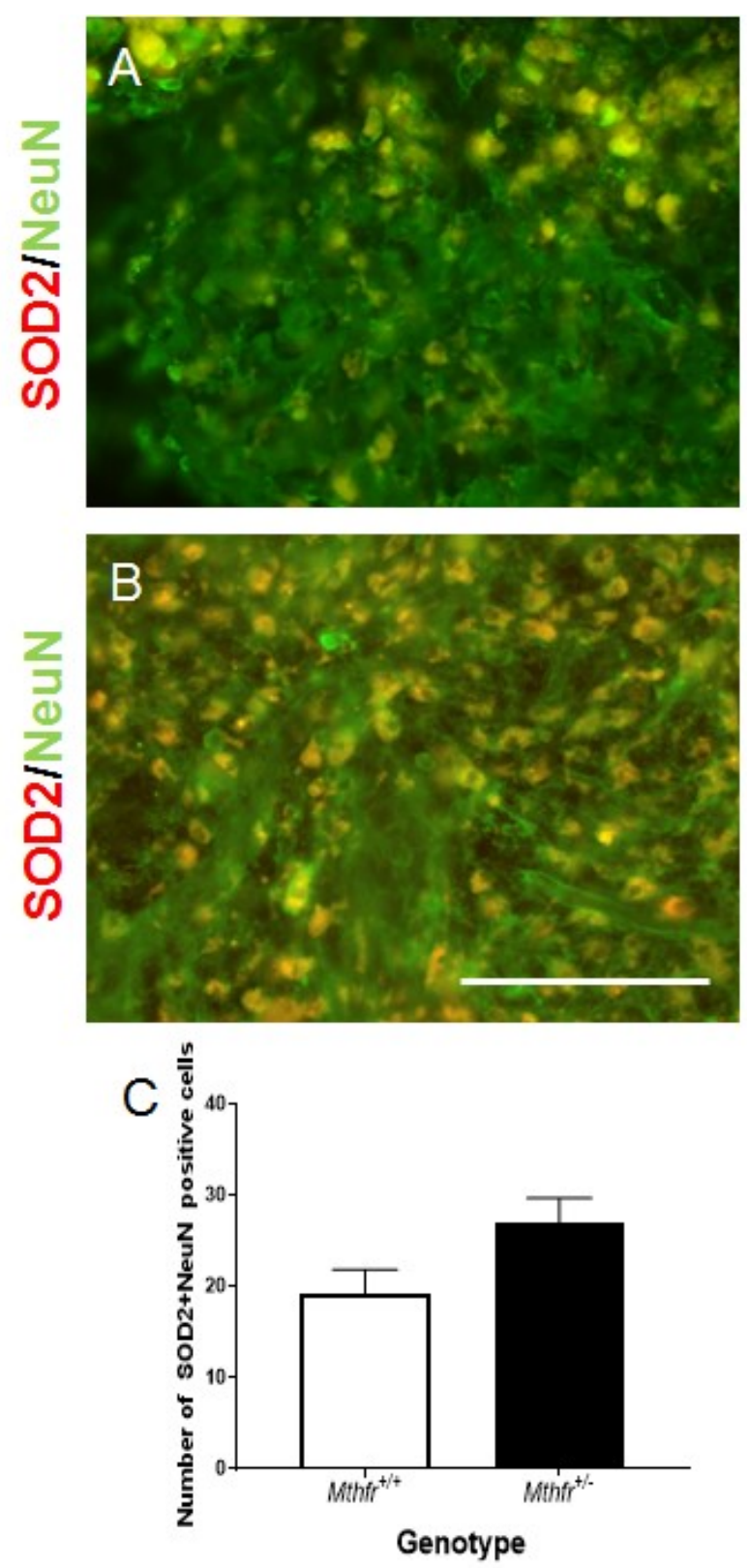

Figure 16. Representative immunofluorescence images of SOD2 and NeuN staining in aged (A) $M t h f r^{+/+}$and (B) $M t h f r^{+/-}$mice after ischemic damage. (C) The number of SOD2 positive cells co-localized with NeuN. Data are expressed as mean \pm SEM in 5-6 mice per group. Scale bar $=100 \mu \mathrm{m}$. 
Microglial activation: $I b a 1+C D 68$

The potential role of microglial cells, which have been previously implicated in ischemic damage (Anttila et al., 2016), was also examined as a potential contributor towards neurodegeneration. Immunofluorescence of microglial cell activation was assessed by colocalization of microglial marker Ibal and CD68, a cytoplasmic marker for microglial macrophages. After ischemic damage, there was no significant difference in microglial cell activation between $M t h f r^{+/}$and $M t h f r^{+/}$mice (Figure 17; $\left.\mathrm{t}_{(8)}=0.98, \mathrm{p}>0.05\right)$. 

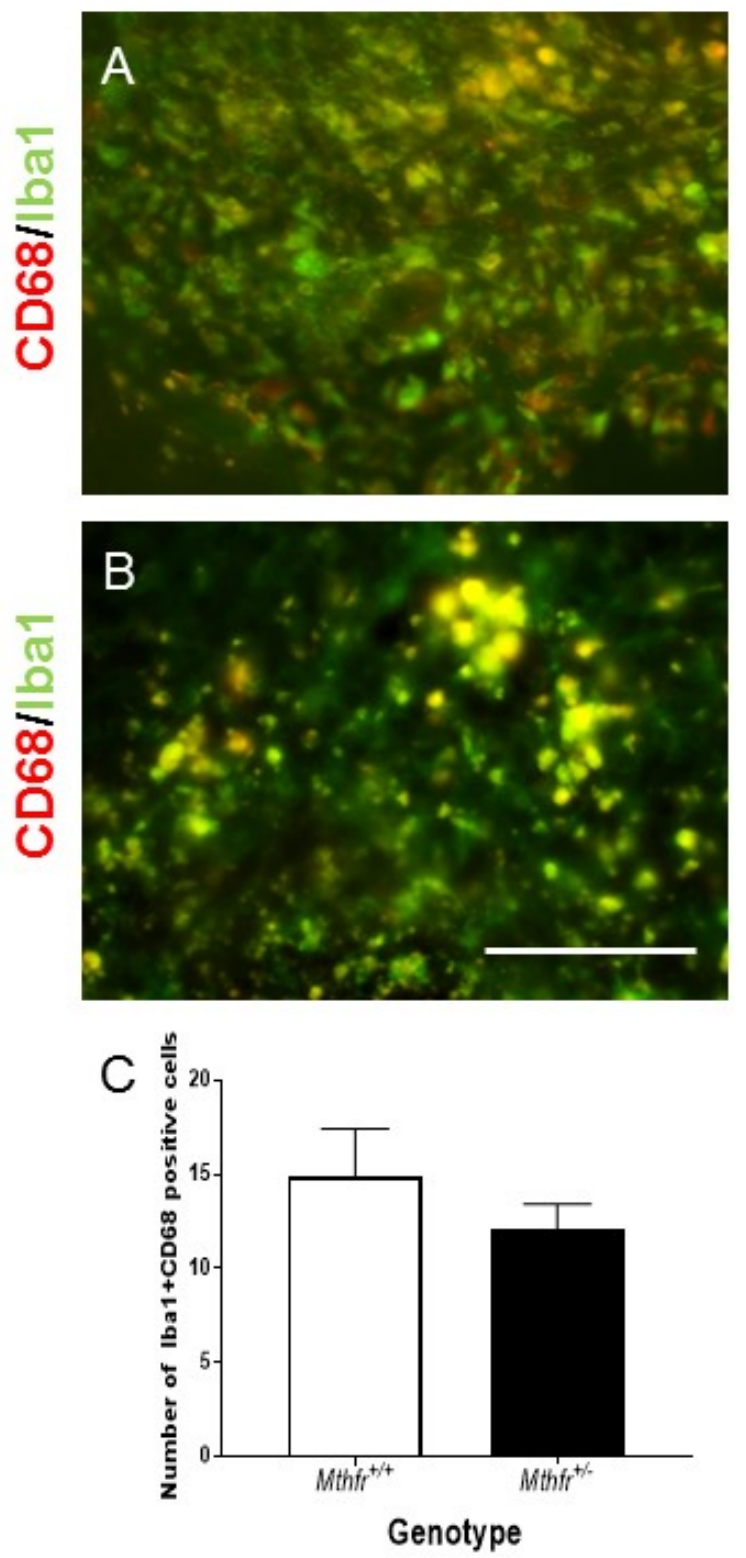

Figure 17. Representative immunofluorescence images of Ibal and CD68 staining in aged (A) $M t h f r^{+/+}$and (B) $M t h f r^{+/-}$mice after ischemic damage. (C) The number of Ibal positive cells co-localized with NeuN. Data are expressed as mean \pm SEM in 5 mice per group. Scale bar $=100 \mu \mathrm{m}$. 


\section{Discussion}

The data from this study suggests that aged $M t h f r^{+/}$mice are more vulnerable to ischemic damage via photothrombosis to the sensorimotor cortex. Repeated in two cohorts of animals, the single pellet reaching task shows greater quantitative and qualitative impairments in skilled forelimb function in $\mathrm{Mthfr}^{+/}$mice for up to five weeks after damage. At five weeks after damage, $M t h f r^{+/-}$mice show no significant impairments in both the quantitative and qualitative aspects of the ladder beam task. Other assessments of motor function at five weeks including the accelerated rotarod and forepaw asymmetry task were not significantly different between groups. Plasma homocysteine concentration in $M t h f r^{+/-}$mice was elevated regardless of photothrombosis damage however no differences in lesion volume were observed between groups five weeks after damage. This study also shows an increase in apoptotic cells at the damage site of $M t h f r^{+/-}$mice via active caspase-3. No differences in p53, nuclear factor-like 2 (Nrf2), superoxide dismutase (SOD2), ionized calcium-binding adapter molecule 1 (Iba1) nor cluster of differentiation 68 (CD68) expression were observed between groups at five weeks after damage.

\section{Worse outcomes from ischemic damage mice may be followed by better chances of rehabilitative recovery}

In agreement with the first hypothesis, $M t h f r^{+/-}$mice showed more severe impairments in motor function from ischemic damage compared to wild-type littermate controls. Neither genotype fully recovered to pre-stroke percent reaching success. Intriguingly, $M t h f r^{+/-}$mice seemed to show signs of recovery while $\mathrm{Mthfr}^{+/+}$mice still showed signs of impairment compared to respective shams. Perhaps at approximately five weeks after damage wild-type mice were still experiencing motor dysfunction while $M t h f r^{+/-}$mice had partially recovered, or could 
recover, more effectively from ischemic damage compared to $M t h f r^{+/+}$for possible reasons explained below.

In this study, there was considerable degree of variability both in behavioural and molecular analysis after ischemic damage using the ladder beam, accelerated rotarod, forepaw asymmetry and lesion volume. Results of these tasks took place at the time point of approximately five weeks after damage and sources of variance may be attributed to multiple factors. Generally, variability in stroke recovery is clinically prevalent and regression models fail to address unexplained variance (Prabhakaran et al., 2008) and so it is likely that inter-individual neuroplasticity in recovery may explain most of this. Damage induced by the photothrombosis model varies increasingly with the time of laser light exposure during surgery (Labat-gest and Tomasi, 2013) and could contribute to an increase of variability in stroke outcome in vivo. In this study, the minimum amount of time of 15 minutes, necessary to induce ischemic damage, was used. In addition, lesion volume had previously reported to decrease over time in the photothrombotic stroke model in C57BL/6 mice (Labat-gest and Tomasi, 2013) indicating a time frame by which lesion volume could have changed in proportion to the inter-individual recovery of each mouse, potentially explaining an increased variance in lesion volume in this study. Prior to beginning experiments, a larger lesion volume in $M t h f r^{+/}$mice compared to $M t h f r^{+/+}$was hypothesized since smaller lesion volumes correlated with improved functional outcomes in stroke patients (Rother et al., 2002; Schiemanck et al., 2005). In contrast, an in vivo study showed improved functional recovery from the ladder beam and rotarod without significant changes in lesion volume after photothrombosis in Wistar rats for up to six weeks (Schäbitz et al., 2004). These findings suggest that lesion volume in vivo varies and may not necessarily reflect stroke outcome. It is also important to note that, while the lesion volume is currently 
regarded as a hallmark measure of stroke outcome, it does not imply the mechanism of its production. Since homocysteine has been associated with DNA damage, future research could further quantify the infarct by a terminal deoxyribonucleotidyl dUTP nick end labelling (TUNEL) stain. One might also consider social aspects of stroke recovery. Because some mice were lost to the damage, few mice were caged by themselves towards the end of the study. When patients suffer from a stroke, having a positive social community or enrichment paired with rehabilitation has been shown to significantly improve motor function (Ru et al., 2017). Similarly in adult mice, social interactions with cage-mates has been shown to reduce depressive behaviours and improve functional outcome after middle cerebral artery occlusion (Venna et al., 2014; Verma et al., 2014). Although most of the mice in the present study were pair housed and had mild enrichment, it is also possible that social aspects could have contributed to unknown variation in stroke outcome. Nonetheless, the amount of variation presented in this study appeared to be consistent with clinical trends in stroke outcome and has been repeated in 2 separate cohorts of animals.

After stroke, repeated practice of a motor skill has shown to improve functional recovery from damage in mice, rats and non-human primates and this increase in plasticity seems to occur within the first month after the stroke event, peaking at 1 week, then shifting into a maintenance phase (Carmichael, 2006; Kerr et al., 2011; Krakauer et al., 2012). Adult C57BL/6 mice focally damaged to the motor cortex by photothrombosis previously demonstrated recovery of skilled reaching after two weeks of weekly reaching and this was coupled with functional reorganization of both forelimb and hindlimb sensorimotor maps (Clarkson et al., 2013). Others for example, showed how continuous daily skilled reaching for five weeks after damage, which almost exclusively forces voluntary use of the impaired forelimb, improves motor function following an 
Endothelin-1 model of stroke to the sensorimotor cortex in Long-Evans rats (Maldonado et al., 2008), so it is likely that skilled reaching in this study may have served as a physical rehabilitative therapy. One meta-analysis of five animal studies including that of Maldonado et al. (2008) reported skilled reaching, starting after the first five days post-stroke, improved limb function by $\sim 27 \%$ (Schmidt et al., 2014) however there appeared to be a time point too early for rehabilitation. Risedal and colleagues reported instead detrimental effects on motor function when forelimb training was started 24 hours after a middle cerebral artery occlusion in rats as opposed to at one week (Risedal et al., 1999). Additionally, when rats are given an enriched cage environment in combination with daily sessions of reach training therapy after Endothelin-1 or middle cerebral artery occlusion, there is a significant rescue of forelimb reaching ability when the rehabilitation was initiated within the first two weeks, but not 30 days, after stroke (Biernaskie and Corbett, 2001; Krakauer et al., 2012). Similar to Krakauer et al. (2012), it is important to also consider the amount of reaching or reaching intensity, permitted after damage, as it significantly affected stroke recovery such that a high intensity regime (twice daily) had shown to further enhance stroke outcome in C57BL mice (Bell et al., 2015; Schuch et al., 2016). In this study, skilled reaching began three to four days after ischemic damage and a low intensity regime of 10 reaches per day is used in this study (Bell et al., 2015), coinciding with an ideal time point for reaching rehabilitation to support functional outcome without enhancing reaching intensity.

Mice and humans that suffer a moderate-severe focal ischemic stroke had a better chance to recover in upper extremity motor function compared to those who suffer a mild stroke (Duncan et al., 1992; Winters et al., 2015) with the assistance of physical rehabilitation and this depended on the intensity, timing and the approach for rehabilitation (Carmichael and Krakauer, 
2013; Zeiler and Krakauer, 2013). For example, a study investigating recovery of 104 stroke patients, categorized by severity with a Fugl-Meyer Assessment (FMA) of sensorimotor function after stroke, was done. Based on a Barthal Index of daily living, moderate-severe and severe stroke patients showed the largest partial recovery, or change scores, of motor function within 30 days whereas mildly impaired individuals experienced little to no benefit (Duncan et al., 1992). These findings along with others have lead to the Proportional Recovery Model, which has been proposed as a general means to predict and understand the degree of recovery from stroke based on the initial impairments in upper extremity motor function. This model uses the change in the recovery score from the initial impairment to predict functional outcome over a time period such as 30 days and to quantify the amount of biological recovery after stroke. Thus far this model accounts for $\sim 70 \%$ stroke cases (Prabhakaran et al., 2008) with a considerable degree of variation. There is a small subset of patients that do not fit this model and are labelled non-fitters because they tended to suffer more severe outcomes within the first 72 hours after stroke and do not recover much afterwards even with rehabilitation therapy.

If indeed $M t h f r^{+/}$mice were more affected by a photothrombotic ischemic damage model, then having shown signs of improved recovery with the assistance of physical rehabilitation via skilled reaching agrees with the concept of the Proportional Recovery Model. This is a clinically relevant and likely explanation for observing more severe impairments of motor function initially followed by no significant impact of damage after five weeks in aged Mthfr ${ }^{+/}$mice. 


\section{A critical window for underlying mechanisms mediating degeneration and protection early after stroke}

To better understand the neurological basis of an increased vulnerability to ischemic damage via photothrombosis to the sensorimotor cortex, this study investigated activity of markers of apoptosis, antioxidant activity as a proxy of redox status and active microglia. All these pathways of effects have been implicated in stroke but have not been explored in chronic time points after stroke.

Caspases play a central role in apoptosis signalling and caspase- 3 in particular is more downstream, inducing DNA fragmentation when activated via cleavage (Fan et al., 2014). This study is one of the first to report continued activation of caspase-3, using an antibody that detects the large fragment of the cleaved protein and the endogenous full-length protein, approximately five weeks after photothrombosis damage in wild-type mice. Previous work reported a significant elevation of caspase-3 protein expression and activity in mice after photothrombosis for up to 24 hours (Kim et al., 2000). This continued activation observed in the present study may be influenced by homocysteine, as it has shown to be an inductor of caspase-dependent neuronal apoptosis by a mechanism involving DNA damage, poly-ADP-ribose polymerase (PARP), and mitochondrial dysfunction by caspase-3 activation (Lehotsky et al., 2014). More importantly, the significantly elevated apoptotic activity at the damage site of aged Mthfr ${ }^{+/-}$mice in this study suggest a potential mechanism that could at least partially explain a more severe stroke outcome.

Intriguingly, p53 activity within cells at the damage site was not significantly different between $M t h f r^{+/-}$and $M t h f r^{+/+}$mice 5 weeks after damage. p53 is a crucial transcription factor associated with DNA damage and apoptosis upstream of caspase- 3 and its function arrests the cell cycle (Crumrine et al., 1994; Wood and Youle, 1995; Kharlamov et al., 1996; Demyanenko 
and Uzdensky, 2016). For up to 24 hours after ischemic insult from photothrombosis to the somatosensory cortex, p53 protein expression was highly upregulated in Wistar rats (Demyanenko and Uzdensky, 2016). In addition, ablation of the p53 gene after middle cerebral artery occlusion in transgenic mice improves functional recovery indicated by reduced infarct volume and increased locomotor behaviours (Filichia et al., 2015). One study investigated the p53 inhibitor pifithrin- $\alpha$ (PFT- $\alpha)$ as a potential therapeutic and when adult Sprague Dawley rats were administered treatment between one and six hours following middle cerebral artery occlusion there was significant reduction in lesion volume and apoptotic cells (Leker et al., 2004). Unfortunately, when PFT- $\alpha$ was administered one week after damage in a similarly designed study, there was no reduction in on cell death within the damage site (Luo et al., 2009). Together, these findings suggest that changes in p53-mediated apoptosis likely occur within the first few days of the damage event and then it follows a sustained and diminishing return. Nonetheless, the present study showed that p53 in photothrombotic stroke model, is activity present in the ischemic core five weeks after damage.

This study reports the activities of nuclear reactive-like factor 2 (Nrf2) and superoxide dismutase (SOD2) in neurons five weeks after damage however there were no significant differences between $\mathrm{Mthfr}^{+/}$and $\mathrm{Mthfr}^{+/+}$mice. These findings are contrary to what was hypothesized: a decrease in antioxidant activity for $\mathrm{Mthfr}^{+/}$mice. Dysregulation of redox balance is one major factor thought exacerbate stroke outcome in an age-related manner (Ungvari et al., 2011) and elevated homocysteine may encourage oxidative damage (Ho et al., 2003). For example, Ho et al. (2003) showed a depletion of the antioxidant glutathione, potentiating ROS in folate-deficient and homocysteine rich embryonic cortical neuron cell cultures. Nrf2 is a transcription factor that upregulates the production of antioxidative enzymes 
and is translocated to the nucleus in the presence of oxidative stress in the brain (Porritt et al., 2012; Sandberg et al., 2014). Similar to elevated plasma homocysteine, dysregulation of Nrf2 has been reported in multiple neurodegenerative pathologies including stroke, Alzheimer's Disease and Parkinson's Disease (Ramsey et al., 2007; de Vries et al., 2008; Sandberg et al., 2014) but is also associated with age-related homeostasis (Ungvari et al., 2011). In the case of stroke in-vivo, Nrf2 deficient C57B/SV129 mice exposed to an Endothelin-1 model were reported to have more severe injuries indicated by increased infarct size and inflammatory responses compared to controls (Shih et al., 2005). Because elevated homocysteine and the dysregulation of Nrf2 were both associated with more severe stroke injuries in mice, perhaps there is an inter-play between homocysteine and Nrf2. While Nrf2 deficiency seems to negatively impact stroke outcome, stimulating the Nrf2 system via sulforaphane after photothrombosis in mice did not alter functional recovery nor infarct volume (Porritt et al., 2012), suggesting that the Nrf2 system of activation plays an important role in protection after ischemia but also has protective limitations. While Nrf2 expression was shown to be upregulated rapidly within 12 hours of a middle cerebral artery occlusion in OKD48 mice and diminishes over the course of the first week (Nakano et al., 2017), this study showed that Nrf2 was still active after five weeks of damage in neurons of the ischemic core in both $M t h f r^{+/}$and Mthfr $r^{+/+}$ mice.

Superoxide dismutase (SOD2, or MnSOD), is an antioxidant enzyme that is located in neurons (Maier and Chan, 2002) and when it is activated in the mitochondrial matrix, it then scavenges reactive oxygen species produced from oxidative damage such as from ischemic stroke (Madamanchi, 2004; Culotta et al., 2006; Chen et al., 2011; Candas and Li, 2014). Similar to elevated plasma homocysteine, reduced SOD2 activity is also reported in numerous 
neurodegenerative pathologies including Alzheimer's Disease, Parkinson's Disease and stroke (Flynn and Mevlov, 2013). In the case of stroke, larger infarcts and elevated cytochrome c, a marker for mitochondrial oxidative damage, for up to 24 hours after permanent middle cerebral artery occlusion was observed in SOD2 knockout mice (Murakami et al., 1998; Fujimura et al., 1999). These findings were also reported in several knockdown studies that showed not only larger lesion volumes and greater neurological deficits but also blood brain barrier disruptions in rodents (Chen et al., 2011). Previous work has reported a 57.9\% reduction in SOD2 activity in the adult cortex of hyperhomocysteineimic rats (Petras et al., 2014). Therefore, a decrease in SOD2 activity was hypothesized to occur and this was not the case for the present study. This study is the first to show functional SOD2 activity in neurons five weeks after photothrombosis, but also in MTHFR deficient mice. The role of pro-oxidative factors are also implicated in ischemia such as ROS (Madamanchi, 2004; Petras et al., 2014). For example, homocysteine may contribute to oxidative damage via homocysteine oxidation, nitrous oxide synthase-mediated ROS production or superoxide dismutase dysfunction (Petras et al., 2014). Elucidation of prooxidative factors could present as an alternative avenue for future studies in post-stroke animals so that the balance between antioxidant and pro-oxidative factors can be profiled.

To grasp the role of inflammatory processes after ischemic damage, this study observed active microglial cell activity at the damage site five weeks after damage. There were no differences in microglial cell activation between $M t h f r^{+/}$and $M t h f r^{+/+}$mice indicated by colocalization of ionized calcium-binding adapter molecule 1 (Iba1) and cluster of differentiation 68 (CD68) and this finding is intriguing because homocysteine is considered a pro-inflammatory upregulator of monocyte chemoattractant protein-1 (MCP-1) and interleukin-8 (IL-8) in stroke (Perla-Kajan et al., 2007; Škovierová et al., 2016). Microglia serve a unique immunoreactive role 
in the central nervous system. After injury such as stroke, microglial cells awake from their dormant state $\left(\mathrm{M}_{1}\right)$ and rapidly produce an inflammatory response, becoming star spindled $\left(\mathrm{M}_{2}\right)$ as well as releasing a series of cytokines and chemokines. These signals trigger the destruction and removal of compromised cells facilitated by macrophagy. Microglia have been described in brain injury but the role of activated microglia in post-ischemic injury remains controversial (Khan et al., 2017). For example, one study compared microglial activation between the middle cerebral artery occlusion and photothrombosis stroke models in mice and reported a delayed microglial activation as well as an accumulation and release of inflammatory cytokines and chemokines including interleukin 6 (IL-6), interleukin 17 (IL-17), intercellular adhesion molecule 1 (ICAM1), macrophage inflammatory protein 1 gamma (MIP-1 $\gamma$ ) as well as tumor necrosis factor receptor 1 and 2 (TNFR1, TNFR2) (Cotrina et al., 2017). In addition, microglia can stimulate both pro- and anti-inflammatory cytokines depending on their environment, however microglial activation via CD68 and Iba1 has previously been reported in the context of ischemic damage in rats exposed to Endothelin-1 (de Geyter et al., 2012; Khan et al., 2017). Most inflammatory processes after ischemic damage such as from stroke occur within the first week and these are followed by downstream pathways of neurodegeneration. In addition, microglial populations change over time with respect to morphology, phenotype and cytokine expression (Ekdahl et al., 2009). For example, Khan et al. (2017) identified a total of 749 genes that were differentially regulated from two to seven days after a photothrombotic stroke in mice and $74.5 \%$ of these genes were related to microglia. At seven days however most of these differentially expressed genes had diminished. This may partially explain why, in this study, there were no differences in microglial activation between $M t h f r^{+/}$and $M t h f r^{+/+}$mice observed five weeks after damage. Nonetheless, these data are the first to show that at, this time point, 
microglial activation was active at the damage site of MTHFR mice after photothrombosis to the sensorimotor cortex.

The overall analysis of immunofluorescence cell counts suggests that, with the except of active caspase-3, molecular signalling of relevant pathways suggested to mediate neurodegeneration and neuroprotection are likely to occur within the first week of the damage event and are either diminished and/or maintained at a certain level of activity regardless of stroke outcome. One alternative confound is that, having recognized the potential for rehabilitation and functional reorganization of the sensorimotor cortex in this study, the number of cells and interested area of tissue could have been affected by these changes. Nonetheless, a MTHFR deficiency and resulting elevated plasma homocysteine, combined with ischemic damage to the sensorimotor cortex, does not appear to affect activity of these pathways five weeks after damage.

\section{A MTHFR deficiency and resulting elevated plasma homocysteine exacerbates stroke outcome in aged mice, not only risk}

While epidemiological findings have identified homocysteine as a significant risk factor of stroke, this study is one of the first to demonstrate in vivo the significant impact of one carbon metabolism on stroke outcome in a more clinically relevant aged mouse model. A MTHFR deficiency mimicking the polymorphism found in at least $5-15 \%$ of the human populations is sufficient to exacerbate dysfunction dealt by ischemic damage. Since there are functional differences in motor behaviours despite having the same amount of damage, this increase in vulnerability to damage may be attributable to a MTHFR deficiency and resulting elevated plasma homocysteine levels. 
As predicted, there was a $\sim 1.6$ fold increase in plasma homocysteine in $M t h f r^{+/}$mice compared to $M t h f r^{+/+}$which has been previously reported when the model was first established (Chen et al., 2001). The true role of elevated homocysteine in stroke as a direct causal agent, indirect causal agent, biomarker and/or a product of damage pathology remains controversial however, in this study, ischemic damage from photothrombosis did not significantly elevate plasma homocysteine concentration, suggesting that homocysteine likely plays more of an indirect role in stroke outcome. Nonetheless, disruption of other factors that may help remove homocysteine such as a MTHFR deficiency also exacerbates the outcomes of neurodegenerative pathologies.

A Chinese clinical study done in extension of Huo et al. (2015) found that the MTHFR CT polymorphism significantly elevates risk of stroke (Zhao et al., 2017) in addition to folate supplementation. In vivo, a MTHFR deficiency with elevated plasma homocysteine mimicked in mice has been previously shown to sensitize mice to endothelial dysfunction and DNA hypomethylation (Devlin et al., 2004; Troen, 2005). Nonetheless, this suggests a potential for the MTHFR polymorphism to exacerbate neurological insults such as from stroke but also potentially, on a bigger scale, other neurodegenerative pathologies. Elevated plasma homocysteine has been associated with several neurodegenerative pathologies including stroke, Alzheimer's Disease and Parkinson's Disease, as well as several mechanisms of homeostatic dysregulation including neurotoxicity, hypomethylation, oxidative stress and inflammation (Obeid and Herrmann, 2006; Petras et al., 2014; Agrawal et al., 2015). So not only is this a plausible possibility but these findings also emphasize the sheer complexity of neuroprotective and neurodegenerative molecular mechanisms and the need to further understand them before developing effective therapeutic approaches. Therefore, a MTHFR deficiency and resulting 
elevated plasma homocysteine likely contributes to an inhospitable environment for neurons, and when subject to damage, worsens the outcome.

\section{Use of aged animals in translational research: influence on stroke outcome and recovery}

The use of animal models more reflective of stroke patients in the clinic should be recognized as an essential factor to accommodate in translational studies given the failure of almost all the hundreds of clinical trials previously done to find more effective stroke therapies. Many of these trials began using younger mice and were unable to pass phase III (Dirnagl, 2016). Since stroke occurs more in seniors aged 65 and above, using aged animal models more reflective of this elderly demographic will, at least in part, help to narrow gaps in translational stroke research.

There is much evidence showing a significant difference in stroke-related traits between young, adult and aged mice. At baseline, there are previously established significant age-related changes including increased body weight, decreased neuromuscular strength shown via the wirehang test and decreased motor function shown via the rotarod as well as an increased anxiety like behaviours shown via the open field test and light/dark transition test (Shoji et al., 2016). In terms of recovery, previous studies using younger mice aged between two to four months reported a recovery period of approximately 14-21 days after photothrombosis (Lee et al., 2007; Clarkson et al., 2013) whereas, in this study, a recovery of approximately 28 days based on percent success from the skilled reaching task, was observed. Since age has shown to limit functional reorganization of the motor cortex after stroke in mice (Tennant et al., 2015), this may explain a longer time required to partially recover. For example, Tennant et al. (2015) induced stroke via Endothelin-1 in both aged and young mice. Their findings showed that aged animals 
had larger lesion volumes and seemed to lack functional reorganization unlike younger mice. Despite a similar ability of young and aged rodents to, for example, perform a meaningful motor task such as skilled reaching, aged animals have shown reduced synaptic potentiation, synaptogenesis and cortical map reorganization in response to experience (Kerr et al., 2011). One of the most intriguing findings in the context of aging in stroke was that the therapeutic window was reportedly significantly smaller (within 3 hours of the stroke event) in aged C57BL/6 mice compared to a 6 hour window in adults when rescuing the endothelial barrier via Percelan domain 5 after photothrombosis (Bix et al., 2013). For example, the domain V treatment significantly reduced the infarct volume and motor dysfunction, shown by a reduced number of foot faults in the grid-walking task and the preference for the impaired paw, compared to untreated controls. In addition, others have reported a decreased inflammatory response, smaller lesion volumes, an elevated microglial response and elevated cell proliferation after a middle cerebral artery occlusion in aged wild-type C57BL/6 mice compared to adults (Sieber et al., 2011; Moraga et al., 2015). Therefore, the use of aged animals in stroke research is clearly justified and this study addresses this confound unlike most work previously done. In future studies, using aged animals should seriously be considered to apply clinical relevance in stroke. 


\section{Conclusion}

Based on the findings of this study and comparing these findings with established literature, elevated plasma homocysteine induced by a MTHFR deficiency significantly exacerbated negative functional outcome following a photothrombotic model of stroke in mice that are more reflective of the elderly demographic in the clinic. This study addresses some of the current gaps in stroke research translation that previous work has lacked. This also implies that, in the case of using folates as a potential and cost-effective therapy for stroke prevention, the proper metabolism of folate also plays a crucial role in reducing stroke outcome. After five weeks, MTHFR deficient mice showed signs of functional recovery possibly due to the rehabilitative effects of the skilled reaching task, agreeing with the proportional recovery model of stroke recovery in the clinic. A MTHFR deficiency likely contributes to the ability of homocysteine to support an inhospitable cellular environment. After damage is dealt, this leaded to a chronic increase in apoptosis. Other mechanisms mediating neurodegeneration, including antioxidant activation and inflammation, were likely undergoing crucial changes closer to the damage event. Future stroke research should recognize the important role of one carbon metabolism in functional outcome following stroke. The research produced from this thesis provides a significant contribution to a foundation of basic science in the advancement of stroke therapeutics and suggests that targeting one-carbon metabolism could serve as an alternative therapeutic approach to prevention and recovery from negative stroke outcome. 


\section{References}

Agrawal A, Ilango K, Singh PK, Karmakar D, Singh GPI, Kumari R, Dubey GP (2015) Age dependent levels of plasma homocysteine and cognitive performance. Behav Brain Res 283:139-144.

Ahmad M, Dar NJ, Bhat ZS, Hussain A, Shah A, Liu H, Graham SH (2014) Inflammation in Ischemic Stroke: Mechanisms, Consequences and Possible Drug Targets. CNS Neurol Disord -Drug Targets 13:1378-1396.

Alawieh A, Wang W, Narang A, Tomlinson S (2016) Thromboembolic Model of Cerebral Ischemia and Reperfusion in Mice. In: Injury Models of the Central Nervous System (Dixon CE, Hayes RL, Walker JM, eds), pp 357-372.

Ansari R, Mahta A, Mallack E, Luo JJ (2014) Hyperhomocysteinemia and neurologic disorders: a review. J Clin Neurol 10:281-288.

Anttila JE, Whitaker KW, Wires ES, Harvey BK, Airavaara M (2016) Role of microglia in ischemic focal stroke and recovery: focus on Toll-like receptors. Prog NeuroPsychopharmacology Biol Psychiatry.

Baccarelli A, Wright R, Bollati V, Litonjua A, Zanobetti A, Tarantini L, Sparrow D, Vokonas P, Schwartz J (2010) Ischemic Heart Disease and Stroke in Relation to Blood DNA Methylation. Epidemiology 21:819-828.

Balkaya M, Kröber J, Gertz K, Peruzzaro S, Endres M (2013) Characterization of long-term functional outcome in a murine model of mild brain ischemia. J Neurosci Methods 213:179-187.

Bell JA, Wolke ML, Ortez RC, Jones TA, Kerr AL (2015) Training intensity impacts motor rehabilitation efficacy following unilateral ischemic insult of the sensorimotor cortex in C57BL/6 mice. Neurorehabil Neural Repair 29:590-598.

Biernaskie J, Corbett D (2001) Enriched rehabilitative training promotes improved forelimb motor function and enhanced dendritic growth after focal ischemic injury. J Neurosci 21:5272-5280.

Bix GJ, Gowing EK, Clarkson AN (2013) Perlecan domain V is neuroprotective and affords functional improvement in a photothrombotic stroke model in young and aged mice. Transl Stroke Res 4:515-523.

Bonaventura A, Montecucco F, Dallegri F (2016) Update on the effects of treatment with recombinant tissue-type plasminogen activator (rt-PA) in acute ischemic stroke. Expert Opin Biol Ther.

Brattstrom L, Lindgren A, Israelsson B, Malinow MR, Norrving B, Upson B, Hamfelt A (1992) Hyperhomocysteinaemia in stroke: prevalence, cause, and relationships to type of stroke and stroke risk factors. Eur J Clin Invest 22:214-221.

Broome LJ et al. (2016) Cognitive Outcomes following Thrombolysis in Acute Ischemic Stroke: A Systematic Review. J Stroke Cerebrovasc Dis 25:2868-2875.

Brosnan JT, Jacobs RL, Stead LM, Brosnan ME (2004) Methylation demand: a key determinant of homocysteine metabolism. Acta Biochim Pol 51:405-413.

Busl KM, Greer DM (2010) Hypoxic-ischemic brain injury: Pathophysiology, neuropathology and mechanisms. NeuroRehabilitation 26:5-13.

Candas D, Li JJ (2014) MnSOD in oxidative stress response-potential regulation via mitochondrial protein influx. Antioxid Redox Signal 20:1599-1617.

Carmichael ST (2006) Cellular and molecular mechanisms of neural repair after stroke: Making 
waves. Ann Neurol 59:735-742.

Carmichael ST, Krakauer JW (2013) The promise of neuro-recovery after stroke: Introduction. Stroke 44:S103.

Castillo-Lancellotti C, Tur J a, Uauy R (2012) Impact of folic acid fortification of flour on neural tube defects: a systematic review. Public Health Nutr 16:1-11.

Castro R, Rivera I, Blom HJ, Jakobs C, Tavares de Almeida I (2006) Homocysteine metabolism, hyperhomocysteinaemia and vascular disease: An overview. J Inherit Metab Dis 29:3-20.

Celtikci B, Leclerc D, Lawrance AK, Deng L, Friedman HC, Krupenko NI, Krupenko SA, Melnyk S, James SJ, Peterson AC, Rozen R (2008) Altered expression of methylenetetrahydrofolate reductase modifies response to methotrexate in mice. Pharmacogenet Genomics 18:577-589.

Chen H, Yoshioka H, Kim GS, Jung JE, Okami N, Sakata H, Maier CM, Narasimhan P, Goeders CE, Chan PH (2011) Oxidative stress in ischemic brain damage: mechanisms of cell death and potential molecular targets for neuroprotection. Antioxid Redox Signal 14:1505-1517.

Chen Z, Karaplis a C, Ackerman SL, Pogribny IP, Melnyk S, Lussier-Cacan S, Chen MF, Pai a, John SW, Smith RS, Bottiglieri T, Bagley P, Selhub J, Rudnicki M a, James SJ, Rozen R (2001) Mice deficient in methylenetetrahydrofolate reductase exhibit hyperhomocysteinemia and decreased methylation capacity, with neuropathology and aortic lipid deposition. Hum Mol Genet 10:433-443.

Christopher R, Nagaraja D, Shankar SK (2007) Homocysteine and cerebral stroke in developing countries. Curr Med Chem 14:2393-2401.

Clarke R, Halsey J, Lewington S, Lonn E, Armitage J, Manson JE, Bønaa KH, Spence JD, Nygård O, Jamison R, Gaziano JM, Guarino P, Bennett D, Mir F, Peto R, Collins R, Collaboration B-VTT (2010) Effects of lowering homocysteine levels with B vitamins on cardiovascular disease, cancer, and cause-specific mortality: Meta-analysis of 8 randomized trials involving 37485 individuals. Arch Intern Med 170:1622-1631.

Clarkson AN, López-Valdés HE, Overman JJ, Charles AC, Brennan K, Carmichael ST (2013) Multimodal Examination of Structural and Functional Remapping in the Mouse Photothrombotic Stroke Model. J Cereb Blood Flow Metab 33:716-723.

Cotrina ML, Lou N, Tome-garcia J, Goldman J, Nedergaard M (2017) Direct comparison of microglial dynamics and inflammatory profile in photothrombotic and arterial occlusion evoked stroke. Neuroscience 343:483-494.

Crumrine RC, Thomas AL, Morgan PF (1994) Attenuation of p53 Expression Protects against Focal Ischemic Damage in Transgenic Mice. J Cereb Blood Flow Metab 14:887-891.

Culotta VC, Yang M, O'Halloran T V. (2006) Activation of superoxide dismutases: Putting the metal to the pedal. Biophys Chem 1763:747-758.

de Geyter D, Stoop W, Zgavc T, Sarre S, Michotte Y, Keyser J De, Kooijman R (2012) Spontaneously hypertensive rats display reduced microglial activation in response to ischemic stroke and lipopolysaccharide. J Neuroinflammation 9:114.

de Vries HE, Witte M, Hondius D, Rozemuller AJM, Drukarch B, Hoozemans J, Horssen J Van (2008) Free Radical Biology \& Medicine Nrf2-induced antioxidant protection : A promising target to counteract ROS-mediated damage in neurodegenerative disease ? Free Radic Biol Med 45:1375-1383.

Demyanenko S, Uzdensky A (2016) Profiling of Signaling Proteins in Penumbra After Focal Photothrombotic Infarct in the Rat Brain Cortex. Mol Neurobiol:1-18.

Desai CK, Huang J, Lokhandwala A, Fernandez A, Riaz I Bin, Alpert JS (2014) The role of 
vitamin supplementation in the prevention of cardiovascular disease events. Clin Cardiol 37:576-581.

Devlin AM, Arning E, Bottiglieri T, Faraci FM, Rozen R, Steven R, Dc W, Devlin AM, Arning E, Bottiglieri T, Faraci FM, Rozen R, Lentz SR (2004) Effect of Mthfr genotype on dietinduced hyperhomocysteinemia and vascular function in mice Effect of Mthfr genotype on diet-induced hyperhomocysteinemia and vascular function in mice. Blood 103:2624-2629.

Dirnagl U (2016) Thomas Willis Lecture: Is Translational Stroke Research Broken, and if So, How Can We Fix It? Stroke 47:2148-2153.

Duncan PW, Goldstein LB, Matchar D, Divine GW, Feussner J (1992) Measurement of motor recovery after stroke. Stroke 23:1084-1089.

Ekdahl CT, Kokaia Z, Lindvall O (2009) Brain inflammation and adult neurogenesis: The dual role of microglia. Neuroscience 158:1021-1029.

Endres M, Ahmadi M, Kruman I, Biniszkiewicz D, Meisel A, Gertz K (2005) Folate deficiency increases postischemic brain injury. Stroke 36:321-325.

Fan W, Dai Y, Xu H, Zhu X, Cai P, Wang L, Sun C, Hu C, Zheng P, Zhao B-Q (2014) Caspase3 Modulates Regenerative Response After Stroke. Stem Cells 32:473-486.

Farr TD, Liu L, Colwell KL, Whishaw IQ, Metz GA (2006) Bilateral alteration in stepping pattern after unilateral motor cortex injury: a new test strategy for analysis of skilled limb movements in neurological mouse models. J Neurosci Methods 153:104-113.

Farr TD, Whishaw IQ (2002) Quantitative and qualitative impairments in skilled reaching in the mouse (Mus musculus) after a focal motor cortex stroke. Stroke 33:1869-1875.

Feigin VL, Mensah GA, Norrving B, Murray CJL, Roth GA (2015) Atlas of the Global Burden of Stroke (1990-2013): The GBD 2013 Study. Neuroepidemiology 45:230-236.

Filichia E, Shen H, Zhou X, Qi X, Jin K, Greig N, Hoffer B, Luo Y (2015) Forebrain neuronal specific ablation of p53 gene provides protection in a cortical ischemic stroke model. Neuroscience 295:1-10.

Fluri F, Schuhmann MK, Kleinschnitz C (2015) Animal models of ischemic stroke and their application in clinical research. Drug Des Devel Ther 9:3445-3454.

Flurkey K, Currer JM, Harrison DE (2007) Mouse Models in Aging Research. In: The Mouse in Biomedical Research, pp 637-672.

Flynn JM, Mevlov S (2013) SOD2 in mitochondrial dysfunction and neurodegeneration. Free Radic Biol Med 62:4-12.

Forti P, Maioli F, Arnone G, Coveri M, Pirazzoli GL, Zoli M, Procaccianti G (2016) Homocysteinemia and early outcome of acute ischemic stroke in elderly patients. 6:e00460.

Frosst P, Blom HJ, Milos R, Goyette P, Sheppard CA, Matthews RG, Boers GJH, den Heijer M, Kluijtmans LAJ, van den Heuvel LP, Rozen R (1995) A candidate genetic risk factor for vascular disease: a common mutation in methylenetetrahydrofolate reductase. Nat Genet 10:196-201.

Fu HJ, Zhao LB, Xue JJ, Wu ZX, Huang YP, Liu W, Gao Z (2015) Elevated Serum Homocysteine (Hcy) Levels May Contribute to the Pathogenesis of Cerebral Infarction. J Mol Neurosci 56:553-561.

Fujimura M, Morita-fujimura Y, Kawase M, Copin J, Calagui B, Epstein CJ, Chan PH (1999) Manganese Superoxide Dismutase Mediates the Early Release of Mitochondrial Cytochrome C and Subsequent DNA Fragmentation after Permanent Focal Cerebral Ischemia in Mice. J Neurosci 19:3414-3422.

Hainsworth AH, Yeo NE, Weekman EM, Wilcock DM (2015) Homocysteine, 
hyperhomocysteinemia and vascular contributions to cognitive impairment and dementia (VCID). Biochim Biophys Acta - Mol Basis Dis 1862:1008-1017.

He W, Lu M, Li G, Sun Z, Liu D, Gu L (2017) Methylene Tetrahydrofolate Reductase (MTHFR) rs868014 Polymorphism Regulated by miR-1203 Associates with Risk and Short Term Outcome of Ischemic Stroke. Cell Physiol Biochem 41:701-710.

Hill MJ (1997) Intestinal flora and endogenous vitamin synthesis. Eur J Cancer Prev 6:S43-45.

Ho PI, Ashline D, Dhitavat S, Ortiz D, Collins SC, Shea TB, Rogers E (2003) Folate deprivation induces neurodegeneration: Roles of oxidative stress and increased homocysteine. Neurobiol Dis 14:32-42.

Holmes M V. et al. (2011) Effect modification by population dietary folate on the association between MTHFR genotype, homocysteine, and stroke risk: A meta-analysis of genetic studies and randomised trials. Lancet 378:584-594.

Huang L, Wu ZB, ZhuGe Q, Zheng W, Shao B, Wang B, Sun F, Jin K (2014) Glial scar formation occurs in the human brain after ischemic stroke. Int J Med Sci 11:344-348.

Huo Y et al. (2015) Efficacy of Folic Acid Therapy in Primary Prevention of Stroke Among Adults With Hypertension in China. JAMA 313:1325.

Imbard A, Benoist J-F, Esse R, Gupta S, Lebon S, De Vriese AS, Ogier De Baulny H, Kruger W, Schiff M, Blom HJ (2015) High homocysteine induces betaine depletion. Biosci Rep 35:e0222.

Isobe C, Murata T, Sato C, Terayama Y (2005) Increase of total homocysteine concentration in cerebrospinal fluid in patients with Alzheimer's disease and Parkinson's disease. Life Sci 77:1836-1843.

Jadavji NM, Deng L, Leclerc D, Malysheva O, Bedell BJ, Caudill M a., Rozen R (2012) Severe methylenetetrahydrofolate reductase deficiency in mice results in behavioral anomalies with morphological and biochemical changes in hippocampus. Mol Genet Metab 106:149-159.

Jadavji NM, Farr TD, Lips J, Khalil AA, Boehm-Sturm P, Foddis M, Harms C, Füchtemeier M, Dirnagl U (2015a) Elevated levels of plasma homocysteine, deficiencies in dietary folic acid and uracil-DNA glycosylase impair learning in a mouse model of vascular cognitive impairment. Behav Brain Res 283:215-226.

Jadavji NM, Wieske F, Dirnagl U, Winter C (2015b) Methylenetetrahydrofolate reductase deficiency alters levels of glutamate and y-aminobutyric acid in brain tissue. Mol Genet Metab Reports 3:1-4.

Jauch EC, Saver JL, Adams HP, Bruno A, Connors JJB, Demaerschalk BM, Khatri P, McMullan PW, Qureshi AI, Rosenfield K, Scott PA, Summers DR, Wang DZ, Wintermark M, Yonas $\mathrm{H}$ (2013) Guidelines for the early management of patients with acute ischemic stroke: A guideline for healthcare professionals from the American Heart Association/American Stroke Association. Stroke 44:870-947.

Jiang B, Chen Y, Yao G, Yao C, Zhao H, Jia X, Zhang Y, Ge J, Qiu E, Ding C (2014) Effects of differences in serum total homocysteine, folate, and vitamin B12 on cognitive impairment in stroke patients. BMC Neurol 14:217.

Joubert BR et al. (2016) Maternal plasma folate impacts differential DNA methylation in an epigenome-wide meta-analysis of newborns. Nat Commun 7:10577.

Kelly-Hayes M, Beiser A, Kase CS, Scaramucci A, D’Agostino RB, Wolf PA (2003) The influence of gender and age on disability following ischemic stroke: The Framingham study. J Stroke Cerebrovasc Dis 12:119-126.

Kerr AL, Cheng SY, Jones TA (2011) Experience-dependent neural plasticity in the adult 
damaged brain. J Commun Disord 44:538-548.

Khan A, Ju F, Xie W, Hafeez MT, Cheng X, Yang Z, Zhu L, Li T, Zhang S (2017)

Transcriptomic analysis reveals differential activation of microglial genes after ischemic stroke in mice. Neuroscience 348:212-227.

Khan M, Jamil K (2008) Study on the conserved and the polymorphic sites of MTHFR using bioinformatices approaches. Trends Bioinforma 1:7-17.

Kharlamov a, Uz T, Joo JY, Manev H (1996) Pharmacological characterization of apoptotic cell death in a model of photothrombotic brain injury in rats. Brain Res 734:1-9.

Kim GW, Sugawara T, Chan PH (2000) Involvement of oxidative stress and caspase-3 in cortical infarction after photothrombotic ischemia in mice. J Cereb Blood Flow Metab 20:16901701.

Kim J, Lee H, Chang N (2002) Hyperhomocysteinemia due to short-term folate deprivation is related to electron microscopic changes in the rat brain. J Nutr 132:3418-3421.

Kim WK, Pae YS (1996) Involvement of N-methyl-d-aspartate receptor and free radical in homocysteine-mediated toxicity on rat cerebellar granule cells in culture. Neurosci Lett 216:117-120.

Kolb B, Whishaw IQ (2011) An Introduction to Brain and Behavior, 3rd ed. New York: Worth Publishers.

Kovalska M, Kovalska L, Tothova B, Mahmood S, Adamkov M, Lehotsky J (2015) Combination of hyperhomocysteinemia and ischemic tolerance in experimental model of global ischemia in rats. J Physiol Pharmacol 66:887-897.

Krakauer JW, Carmichael ST, Corbett D, Wittenberg GF (2012) Getting Neurorehabilitation Right: What can be learned from animal models? Neurorehabil Neural Repair 26:923-931.

Kumar A, Aakriti, Gupta V (2016) A Review on Animal Models of Stroke: an Update. Brain Res Bull 122:35-44.

Kumar A, Kumar P, Prasad M, Sagar R, Yadav AK, Pandit AK, Jali VP, Pathak A (2015) Association of C677T polymorphism in the methylenetetrahydrofolate reductase gene (MTHFR gene) with ischemic stroke: A meta analysis. Neurol Res 37:568-577.

Labat-gest V, Tomasi S (2013) Photothrombotic ischemia: a minimally invasive and reproducible photochemical cortical lesion model for mouse stroke studies. J Vis Exp 76:16.

Lawrance AK, Racine J, Deng L, Wang X, Lachapelle P, Rozen R (2011) Complete deficiency of methylenetetrahydrofolate reductase in mice is associated with impaired retinal function and variable mortality, hematological profiles, and reproductive outcomes. J Inherit Metab Dis 34:147-157.

Lee JK, Park MS, Kim YS, Moon KS, Joo SP, Kim TS, Kim JH, Kim SH (2007) Photochemically induced cerebral ischemia in a mouse model. Surg Neurol 67:620-625.

Lees KR, Bluhmki E, von Kummer R, Brott TG, Toni D, Grotta JC, Albers GW, Kaste M, Marler JR, Hamilton SA, Tilley BC, Davis SM, Donnan GA, Hacke W (2010) Time to treatment with intravenous alteplase and outcome in stroke: an updated pooled analysis of ECASS, ATLANTIS, NINDS, and EPITHET trials. Lancet 375:1695-1703.

Lehotsky J, Petras M, Kovalska M, Tothova B, Drgova A, Kaplan P (2014) Mechanisms Involved in the Ischemic Tolerance in Brain: Effect of the Homocysteine. Cell Mol Neurobiol 35:7-15.

Leker RR, Aharonowiz M, Greig NH, Ovadia H (2004) The role of p53-induced apoptosis in cerebral ischemia : effects of the p53 inhibitor pifithrin a. Exp Neurol 187:478-486. 
Liu R, Yuan H, Yuan F, Yang S-H (2012) Neuroprotection targeting ischemic penumbra and beyond for the treatment of ischemic stroke. Neurol Res 34:331-337.

Long X, Lou Y, Gu H, Guo X, Wang T, Zhu Y, Zhao W, Ning X, Li B, Wang J, An Z (2016) Mortality, Recurrence, and Dependency Rates Are Higher after Acute Ischemic Stroke in Elderly Patients with Diabetes Compared to Younger Patients. Front Aging Neurosci 8:1-7.

Luo Y, Kuo C, Shen H, Chou J, Greig NH, Hoffer BJ, Wang Y (2009) Delayed Treatment with a p53 Inhibitor Enhances Recovery in Stroke Brain. Ann Neurol 65:520-530.

Madamanchi NR (2004) Oxidative Stress and Vascular Disease. Arterioscler Thromb Vasc Biol. Maier CM, Chan PAKH (2002) Role of Superoxide Dismutases in Oxidative Damage and Neurodegenerative Disorders. Neurosci 8:323-334.

Maldonado MA, Allred RP, Felthauser EL, Jones TA (2008) Motor Skill Training, but not Voluntary Exercise, Improves Skilled Reaching After Unilateral Ischemic Lesions of the Sensorimotor Cortex in Rats. Neurorehabil Neural Repair 22:250-261.

McIlroy SP, Dynan KB, Lawson JT, Patterson CC, Passmore AP (2002) Moderately elevated plasma homocysteine, methylenetetrahydrofolate reductase genotype, and risk for stroke, vascular dementia, and Alzheimer disease in Northern Ireland. Stroke 33:2351-2356.

Meschia JF, Bushnell C, Boden-Albala B, Braun LT, Bravata DM, Chaturvedi S, Creager MA, Eckel RH, Elkind MS V, Fornage M, Goldstein LB, Greenberg SM, Horvath SE, Iadecola C, Jauch EC, Moore WS, Wilson JA (2014) Guidelines for the primary prevention of stroke: A statement for healthcare professionals from the American heart association/American stroke association. Stroke 45:3754-3832.

Metz GA, Whishaw IQ (2002) Cortical and subcortical lesions impair skilled walking in the ladder rung walking test: A new task to evaluate fore- and hindlimb stepping, placing, and co-ordination. J Neurosci Methods 115:169-179.

Mizrahi EH, Fleissig Y, Arad M, Adunsky A (2005) Plasma homocysteine level and functional outcome of patients with ischemic stroke. Arch Phys Med Rehabil 86:60-63.

Moraga A, Pradillo JM, García-Culebras A, Palma-Tortosa S, Ballesteros I, Hernández-Jiménez M, Moro MA, Lizasoain I (2015) Aging increases microglial proliferation, delays cell migration, and decreases cortical neurogenesis after focal cerebral ischemia. $\mathrm{J}$ Neuroinflammation 12:87.

Morris MS (2003) Homocysteine and Alzheimer's disease. Lancet Neurol 2:425-428.

Mozaffarian D et al. (2015) Heart Disease and Stroke Statistics-2016 Update: A Report From the American Heart Association.

Murakami K, Kondo T, Kawase M, Li Y, Sato S, Chen SF, Chan PH (1998) Mitochondrial susceptibility to oxidative stress exacerbates cerebral infarction that follows permanent focal cerebral ischemia in mutant mice with manganese superoxide dismutase deficiency. $\mathrm{J}$ Neurosci 18:205-213.

Nakano Y, Yamashita T, Li Q, Sato K, Ohta Y (2017) Time-dependent Change of In Vivo Optical Imaging of Oxidative Stress in a Mouse Stroke Model. J Neurosci Res 0:00-00.

Obeid R, Herrmann W (2006) Mechanisms of homocysteine neurotoxicity in neurodegenerative diseases with special reference to dementia. FEBS Lett 580:2994-3005.

Obeid R, McCaddon A, Herrmann W (2007) The role of hyperhomocysteinemia and B-vitamin deficiency in neurological and psychiatric diseases. Clin Chem Lab Med 45:1590-1606.

Obeid R, Schadt A, Dillmann U, Kostopoulos P, Fassbender K, Herrmann W (2009) Methylation status and neurodegenerative markers in Parkinson disease. Clin Chem 55:1852-1860.

Olszewski AJ, McCully KS (1993) Homocysteine metabolism and the oxidative modification of 
proteins and lipids. Free Radic Biol Med 14:683-693.

Pavlovicova M, Kovalska M, Tatarkova Z, Sivonova-Kmetova M, Kaplan P, Lehotsky J (2012) Calcium transporters and their role in the development of neuronal disease and neuronal damage. Gen Physiol Biophys 30:S61-S69.

Perla-Kajan J, Twardowski T, Jakubowski H, Perła-Kaján J, Twardowski T, Jakubowski H (2007) Mechanisms of homocysteine toxicity in humans. Amino Acids 32:561-572.

Petras M, Tatarkova Z, Kovalska M, Mokra D, Dobrota D, Lehotsky J, Drgova A (2014) Hyperhomocysteinemia as a risk factor for the neuronal system disorders. J Physiol Pharmacol 65:15-23.

Pniewski J, Chodakowska-Zebrowska M, Wozniak R, Stepien K, Stafiej A (2003) Plasma homocysteine level and the course of ischemic stroke. Acta Neurobiol Exp (Wars) 63:127130.

Porritt MJ, Andersson HC, Hou L, Nilsson A, Pekna M, Pekny M, Nilsson M (2012) Photothrombosis-Induced Infarction of the Mouse Cerebral Cortex Is Not Affected by the Nrf2-Activator Sulforaphane. PLoS One 7:e41090.

Prabhakaran S, Zarahn E, Riley C, Speizer A, Chong JY, Lazar RM, Marshall RS, Krakauer JW (2008) Inter-individual Variability in the Capacity for Motor Recovery After Ischemic Stroke. Neurorehabil Neural Repair 22:64-71.

Ramsey CP, Glass CA, Montgomery MB, Lindl KA, Ritson GP, Chia LA, Hamilton RL, Chu CT, Jordan-Sciutto KL (2007) Expression of Nrf2 in Neurodegenerative Diseases. J Neuopathol Exp Neurol 66:75-85.

Risedal A, Zeng J, Johansson BB (1999) Early Training May Exacerbate Brain Damage After Focal Brain Ischemia in the Rat. J Cereb Blood Flow Metab:997-1003.

Rossi M, Amaretti A, Raimondi S (2011) Folate production by probiotic bacteria. Nutrients 3:118-134.

Rother J, Schellinger PD, Gass A, Siebler M, Villringer A, Fiebach JB, Fiehler J, Jansen O, Kucinski T, Schoder V, Szabo K, Junge-Hulsing GJ, Hennerici M, Zeumer H, Sartor K, Weiller C, Hacke W (2002) Effect of intravenous thrombolysis on MRI parameters and functional outcome in acute stroke $<6$ hours. Stroke 33:2438-2445.

Ru X, Dai H, Jiang B, Li N, Zhao X, Hong Z, He L, Wang W (2017) Community-Based Rehabilitation to Improve Stroke Survivors' Rehabilitation Participation and Functional Recovery. Am J Phys Med Rehabil 96:e123-e129.

Sacco RL et al. (2013) An updated definition of stroke for the 21st century: A statement for healthcare professionals from the American heart association/American stroke association. Stroke 44:2064-2089.

Sandberg M, Patil J, D'Angelo B, Weber SG, Mallard C (2014) NRF2-regulation in brain health and disease: Implication of cerebral inflammation. Neuropharmacology 79:298-306.

Santilli F, Davì G, Patrono C (2016) Homocysteine, methylenetetrahydrofolate reductase, folate status and atherothrombosis: A mechanistic and clinical perspective. Vascul Pharmacol 78:1-9.

Saposnik G, Ray JG, Sheridan P, McQueen M, Lonn E (2009) Homocysteine-lowering therapy and stroke risk, severity, and disability: Additional findings from the HOPE 2 trial. Stroke 40:1365-1372.

Sarecka-Hujar B, Kopyta I, Pienczk-Reclawowicz K, Reclawowicz D, Emich-Widera E, Pilarska E (2012) The TT genotype of methylenetetrahydrofolate reductase $677 \mathrm{C}>\mathrm{T}$ polymorphism increases the susceptibility to pediatric ischemic stroke: Meta-analysis of the 822 cases and 
1,552 controls. Mol Biol Rep 39:7957-7963.

Schäbitz WR, Berger C, Kollmar R, Seitz M, Tanay E, Kiessling M, Schwab S, Sommer C (2004) Effect of Brain-Derived Neurotrophic Factor Treatment and Forced Arm Use on Functional Motor Recovery after Small Cortical Ischemia. Stroke 35:992-997.

Schiemanck SK, Post MWM, Kwakkel G, Witkamp TD, Kappelle LJ, Prevo AJH (2005) Ischemic lesion volume correlates with long-term functional outcome and quality of life of middle cerebral artery stroke survivors. Restor Neurol Neurosci 23:257-263.

Schmidt A, Wellmann J, Schilling M, Strecker J-K, Sommer C, Schabitz W-R, Diederich K, Minnerup J (2014) Meta-analysis of the Efficacy of Different Training Strategies in Animal Models of Ischemic Stroke. Stroke 45:239-247.

Schneider JA, Rees DC, Liu Y, Clegg JB (1998) Worldwide Distribution of a common methylenetetrahydrofolate reductase mutation. Am J Hum Genet 62:1254-1258.

Schuch CP, Jeffers MS, Antonescu S, Nguemeni C, Gomez-Smith M, Pereira LO, Morshead CM, Corbett D (2016) Enriched rehabilitation promotes motor recovery in rats exposed to neonatal hypoxia-ischemia. Behav Brain Res 304:42-50.

Schwammenthal Y, Tanne D (2004) Homocysteine, B-vitamin supplementation, and stroke prevention: From observational to interventional trials. Lancet Neurol 3:493-495.

Seshadri S, Beiser a (2002) Plasma homocysteine as a risk factor for dementia and Alzheimer's disease. N Engl J Med 346:476-483.

Shi Z, Guan Y, Huo YR, Liu S, Zhang M, Lu H, Yue W, Wang J, Ji Y (2015) Elevated Total Homocysteine Levels in Acute Ischemic Stroke Are Associated with Long-Term Mortality. Stroke 46:2419-2425.

Shih AY, Li P, Murphy TH (2005) A Small-Molecule-Inducible Nrf2-Mediated Antioxidant Response Provides Effective Prophylaxis against Cerebral Ischemia In Vivo. J Neurosci 25:10321-10335.

Shoji H, Takao K, Hattori S, Miyakawa T (2016) Age-related changes in behavior in C57BL/6J mice from young adulthood to middle age. Mol Brain 9:11.

Sieber MW, Claus RA, Witte OW, Frahm C (2011) Attenuated inflammatory response in aged mice brains following stroke. PLoS One 6:1-11.

Škovierová H, Vidomanová E, Mahmood S, Sopková J, Drgová A, Červeňová T, Halašová E, Lehotský J (2016) The Molecular and Cellular Effect of Homocysteine Metabolism Imbalance on Human Health. Int J Mol Sci 17:1733.

Smith AD, Refsum H (2016) Homocysteine, B Vitamins, and Cognitive Impairment. Annu Rev Nutr 36:211-239.

Sommer CJ (2017) Ischemic stroke : experimental models and reality. Acta Neuropathol 133:245-261.

Song Y, Li B, Wang C, Wang P, Gao X, Liu G (2016) Association between 5,10Methylenetetrahydrofolate Reductase C677T Gene Polymorphism and Risk of Ischemic Stroke: A Meta-analysis. J Stroke Cerebrovasc Dis 25:679-687.

Spence JD (2007) Homocysteine-lowering therapy: a role in stroke prevention? Lancet Neurol 6:830-838.

Tennant KA, Kerr AL, Adkins DL, Donlan N, Thomas N, Kleim JA, Jones TA (2015) AgeDependent Reorganization of Peri-Infarct "Premotor" Cortex With Task-Specific

Rehabilitative Training in Mice. Neurorehabil Neural Repair 29:193-202.

The Homocysteine Studies Collaboration (2002) Homocysteine and Risk of Ischemic Heart Disease and Stroke. Am Med Assoc 288:2015-2023. 
Theoret JK, Jadavji NM, Zhang M, Smith PD (2015) Granulocyte macrophage colony stimulating factor treatment results in recovery of motor function after white matter damage in mice. Eur J Neurosci:1-8.

Traystman RJ (2003) Animal Models of Focal and Global Cerebral Ischemia. 44:85-95.

Troen AM (2005) The central nervous system in animal models of hyperhomocysteinemia. Prog Neuro-Psychopharmacology Biol Psychiatry 29:1140-1151.

Troen AM, Shea-Budgell M, Shukitt-Hale B, Smith DE, Selhub J, Rosenberg IH (2008) Bvitamin deficiency causes hyperhomocysteinemia and vascular cognitive impairment in mice. Proc Natl Acad Sci U S A 105:12474-12479.

Ungvari Z, Bailey-downs L, Sosnowska D, Gautam T, Koncz P, Losonczy G, Ballabh P, Cabo R De, Sonntag WE, Csiszar A (2011) Vascular oxidative stress in aging : a homeostatic failure due to dysregulation of NRF2-mediated antioxidant response. Am J Pysiol Hear Circ Physiol 301:H363-H372.

Venna VR, Xu Y, Doran SJ, Patrizz A, McCullough LD (2014) Social interaction plays a critical role in neurogenesis and recovery after stroke. Transl Psychiatry 4:e351.

Verma R, Friedler BD, Harris NM, McCullough LD (2014) Pair housing reverses post-stroke depressive behavior in mice. Behav Brain Res 269:155-163.

Vijayan M, Reddy PH (2016) Peripheral biomarkers of stroke: Focus on circulatory microRNAs. Biochim Biophys Acta - Mol Basis Dis 1862:1984-1993.

Wald DS, Law M, Morris JK (2002) Homocysteine and cardiovascular disease: evidence on causality from a meta-analysis. Bmj 325:1202.

Watson BD, Dietrich WD, Busto R, Wachtel MS, Ginsberg MD (1985) Induction of reproducible brain infarction by photochemically initiated thrombosis. Ann Neurol 17:497504.

WHO MONICA Project Principal Investigators (1988) The world health organization monica project (monitoring trends and determinants in cardiovascular disease): A major international collaboration. J Clin Epidemiol 41:105-114.

Winters C, van Wegen EEH, Daffertshofer A, Kwakkel G (2015) Generalizability of the Proportional Recovery Model for the Upper Extremity After an Ischemic Stroke. Neurorehabil Neural Repair 29:614-622.

Wood KA, Youle RJ (1995) The Role of Free Radicals and p53 in Neuron Apoptosis in vivo. J Neurosci 15:5851-5857.

Yang L-K, Wong K-C, Wu M-Y, Liao S-L, Kuo C-S, Huang R-FS (2007) Correlations between folate, B12, homocysteine levels, and radiological markers of neuropathology in elderly post-stroke patients. J Am Coll Nutr 26:272-278.

Yuan R-YY, Sheu J-JJ, Yu J-MM, Hu C-JJ, Tseng I-JJ, Ho C-SS, Yeh C-YY, Hung Y-LL, Chiang T-RR (2009) Methylenetetrahydrofolate reductase polymorphisms and plasma homocysteine in levodopa-treated and non-treated Parkinson's disease patients. J Neurol Sci 287:64-68.

Zeiler SR, Krakauer JW (2013) The interaction between training and plasticity in the poststroke brain. Curr Opin Neurol 26:609-616.

Zhang Y, Zhu T, Wang L, Pan YH, Zhang S (2013) Homocysteine homeostasis and betainehomocysteine S-methyltransferase expression in the brain of hibernating bats. PLoS One 8:e85632.

Zhao M, Wang X, He M, Qin X, Tang G, Huo Y, Li J, Fu J, Huang X, Cheng X, Wang B, Hou FF, Sun N, Cai Y (2017) Homocysteine and Stroke Risk. Stroke 48:1183-1190. 
Page 91 